\title{
Modelling of multi-component kerosene and surrogate fuel droplet heating and evaporation characteristics: a comparative analysis
}

\author{
L. Poulton ${ }^{\mathrm{a}}$, O. Rybdylova ${ }^{\mathrm{a}}$, I.A. Zubrilin ${ }^{\mathrm{b}}$, S.G. Matveev ${ }^{\mathrm{b}}$, N.I Gurakov ${ }^{\mathrm{b}}$, \\ M. Al Qubeissic, ${ }^{c, d}$ N. Al-Esawic, T. Khan ${ }^{\mathrm{e}}$, V.M. Gun'kof , S.S. Sazhin ${ }^{\mathrm{a}, *}$ \\ ${ }^{a}$ Advanced Engineering Centre, School of Computing, Engineering and Mathematics, \\ University of Brighton, Brighton, BN2 4GJ, UK \\ ${ }^{b}$ Samara National Research University, 34, Moskovskoye Shosse, Samara, 443086, Russia \\ ${ }^{c}$ Institute for Future Transport and Cities, Coventry University, Coventry, CV1 5FB, UK \\ ${ }^{d}$ School of Mechanical, Aerospace and Automotive Engineering, Faculty of Engineering, \\ Environment and Computing, Coventry University, Coventry, CV1 2JH, UK \\ ${ }^{e}$ Institute of Space Technology, P.O. Box 2750, Islamabad 44000, Pakistan \\ ${ }^{f}$ Chuiko Institute of Surface Chemistry, 17 General Naumov Street, Kiev 03164, Ukraine
}

\begin{abstract}
A Discrete Component Model (DCM) is applied to study the heating and evaporation of suspended kerosene and kerosene surrogate droplets. The effects of natural convection are taken into account using the Churchill approximation, whilst the effects of heat addition from the supporting fibre are modelled using the assumption that heat supplied via the fibre is uniformly distributed within the droplet volume. The results of taking into account and ignoring the above effects are investigated. It is shown that the effect of supporting fibre can be ignored in the analysis of these droplets. In contrast, the effect of natural convection cannot be ignored. The time evolution of droplet radii predicted by the DCM, taking into account the effects of natural convection and supporting fibre, is shown to be close to experimental predictions of this parameter for gas temperatures in the range $500^{\circ} \mathrm{C}$ to $700^{\circ} \mathrm{C}$. The heating and evaporation of kerosene droplets are compared with those for droplets of various kerosene surrogate fuels, including eleven surrogate fuels proposed in the literature, and two original compositions. Considering the
\end{abstract}

\footnotetext{
* Corresponding author

Email address: S.Sazhin@brighton.ac.uk (S.S. Sazhin )
} 
balance between the heating and evaporation characteristics of droplets we conclude that those of the original surrogate SU1 and the modified Utah surrogate are the closest to those of kerosene droplets.

Keywords: Discrete Component Model, Droplets, Heating, Evaporation, Kerosene, Natural convection, Surrogates

\section{Introduction}

The importance of using surrogates to approximate kerosene and jet fuels has been widely discussed in the literature [1, 2, 3, 4, 5, 6, 7]. In most cases the development of these surrogates has focused on mimicking the chemical

5 properties of actual fuels. Both chemical and thermophysical properties have been taken into account in relatively few papers (e.g. [ 8, 9]), although the practical importance of modelling thermophysical processes (e.g. heating and evaporation of droplets) in practical engineering applications is commonly recognised [10].

10 An attempt to develop surrogates of FACE A gasoline fuel which could effectively mimic both its chemical and physical properties was made in [1]. In that paper, one of the key requirements was that the heating and evaporation characteristics of surrogate and FACE A gasoline fuels, under conditions relevant to internal combustion engines, should be similar. The Discrete 15 Component Model (DCM), based on the analytical solutions to the equations describing transfer of heat and species diffusion inside fuel droplets, together with the effective thermal conductivity and effective diffusivity models (see [10, 12] for the details), was used in the analysis of [11]. In most cases, this model was based on the assumption that droplets could be approximated by spheres; preliminary investigations of the applicability of a simplified version of this model to spheroidal droplets are discussed in [13. This model has mainly been applied to automotive fuel droplets although the usefulness of its application to water droplets has also been clearly demonstrated [14, 15]. The implementation of this model in ANSYS Fluent CFD code is described in [16, 17].

This paper is focused on the application of the DCM to kerosene and kerosene surrogate droplets. The interest in the problem of heating and evaporation of these droplets and sprays has been mainly stimulated by the importance of these processes in kerosene combustion in propulsion systems [18. Amongst the most recent studies of these processes we mention: those 
presented in [19, 20, 21], focused on experimental studies of the evaporation characteristics of kerosene gel droplets and optimisation of kerosene ignition and combustion characteristics via addition of solid nano-particles; those presented in [22], focused on numerical studies of kerosene sprays with bio-oil additives; those in [23], focused on the numerical study of an oblique detonation wave in a two-phase kerosene-air mixture; and in [24], focused on numerical studies of the ignition of a single kerosene droplet. Although all these and similar studies have made important contributions to our understanding of the processes, most of their attention has been on the gas phase while rather simplistic models have been used for the analysis of the liquid phase. For example the temperature and species concentration gradients inside droplets have been commonly ignored, although this assumption has not been rigorously justified to the best of our knowledge. The focus of our paper will be on modelling the effects of these gradients using models previously developed mainly for automotive applications, and mostly unknown to the aeronautical community.

The composition of kerosene, and simplifications used in our analysis, are discussed in the next section. This is followed in Section 3 by a description of the models used in our study. In Section 4 the predictions of the models are compared with experimental data. Kerosene surrogates, inferred mainly from their chemical characteristics, are described in Section 5. A comparison between surrogate and kerosene droplet heating/evaporation characteristics, under the same conditions as in the experiment described in [25], is presented in Section 6. A summary of the results is presented in Section 7.

\section{Composition of kerosene}

The composition of kerosene analysed by Lissitsina et al. [26], based on 'comprehensive two-dimensional gas chromatography coupled with time-offlight mass spectrometry', is used in our analysis. This composition of 57 components for kerosene sample K1, inferred from Table 6 of [26], is shown in Table 1 .

A simplified version of this composition, using 40 components is shown in Table 2. When presenting the results of [26] in Table 2 three simplifying assumptions were made. Firstly, the contributions of n-alkanes (paraffins) and iso-alkanes were not distinguished. Secondly, the contributions of mono-, di- and tri-naphthenes/olefins were not distinguished. Thirdly, naphthalenes, biphenyls and fluorenes were treated as the same substances as diaromatics. 


\begin{tabular}{|c||c|c|c|c|c|c|c|}
\hline CN & $n$-Alk & iso-Alk & Cyclo & iso-Cyclo & AlkyB & NaphtoB & Naphtha \\
\hline \hline C7 & 0.3092 & 0.3743 & 0.2823 & 0 & 0.1592 & 0 \\
C8 & 0.2712 & 0.5568 & 0.9155 & 0 & 0.9366 & 0 \\
C9 & 0.623 & 2.1869 & 2.5316 & 0.5296 & 2.1157 & 0.2984 \\
C10 & 0.8023 & 4.6876 & 5.4172 & 1.3601 & 3.3035 & 1.2874 \\
C11 & 0.7824 & 5.5606 & 3.9842 & 3.3395 & 2.4082 & 1.9904 \\
C12 & 1.1009 & 6.0985 & 3.9428 & 3.2259 & 3.0139 & 3.4961 \\
C13 & 0.7695 & 4.4756 & 2.7631 & 1.2519 & 2.6909 & 0 \\
C14 & 0.7315 & 4.2249 & 2.9976 & 0.1495 & 1.4904 & 0.8322 \\
C15 & 0.4376 & 4.322 & 1.2012 & 0.093 & 0.2792 & 0.2056 \\
C16 & 0.036 & 1.5195 & 0.5376 & 0 & 0 & 0 & 0.3129 \\
C17 & 0 & 0 & 0.3282 & 0 & 0 & 0 & 0 \\
\end{tabular}

Table 1: Molar fractions of the components of kerosene sample K1 (in percent), adapted from Table 6 of [26]. CN stands for carbon number of a component, $n$-Alk for n-alkanes, iso-Alk for isomers of alkanes, Cyclo for cycloalkanes, iso-Cyclo for isomers of cycloalkanes, AlkyB for alkylbenzenes, NaphtoB for naphtobenzenes, Naphtha for naphthalenes.

This was justified by the closeness of the thermodynamics and transport properties of these components.

Further simplification of the results shown in Tables 1 and 2 can be per-

70 formed based on the observation that the structure and thermodynamic/transport properties of naphthenes are close to those of cycloalkanes. Olefins are chemically different from cycloalkanes, but it is difficult to separate naphthenes and olefins based on the methods used in [26]. This justifies our assumption that all properties of naphthenes/olefins can be approximated by those of cycloalkanes. The properties of naphtobenzenes can be assumed to be close to those of indanes \& tetralines, and the properties of all diaromatics can be assumed close to those of naphthalene [27.

These assumptions, referring to paraffins as alkanes, and using molar fractions instead of mass fractions, allow us to present the results shown in

80 Table 2 in an alternative format as shown in Section 3 (Table 36) of the Supplementary Material. The particular attractiveness of the latter table lies in the fact that the properties of the components mentioned in this table were presented in our earlier paper [28] although for different ranges of carbon numbers.

85 Later in this paper, the predictions of the model based on kerosene compositions inferred from Tables 1 and 2 will be compared. The thermodynamic and transport properties of the components used in Table 1, which will be mostly used in our analysis, are presented in Section 1 of the Supplementary Material. In Section 4 of the Supplementary Material, typos found in the formulae in [28] are identified. 


\begin{tabular}{|c||c|c|c|c|c|}
\hline CN & Par & Na/Ol & Alk & Napht & Dia \\
\hline \hline C7 & 0.4100 & 0.1700 & 0.0900 & 0 & 0 \\
C8 & 0.5800 & 0.6300 & 0.6100 & 0 & 0 \\
C9 & 2.2100 & 2.3700 & 1.5600 & 0.2200 & 0 \\
C10 & 4.7900 & 5.8300 & 2.7200 & 1.0600 & 0.0900 \\
C11 & 6.0900 & 6.9300 & 2.1900 & 1.8100 & 0.2500 \\
C12 & 7.5200 & 7.4000 & 3.0000 & 3.4800 & 0.3000 \\
C13 & 5.9300 & 4.4900 & 2.9100 & 0.9000 & 0.0600 \\
C14 & 6.0300 & 3.7800 & 1.7400 & 0.2400 & 0 \\
C15 & 6.2100 & 1.6700 & 0.3500 & 0 & 0 \\
C16 & 2.1600 & 0.7400 & 0 & 0 & 0 \\
C17 & 0 & 0.4800 & 0 & 0 & 0 \\
\hline
\end{tabular}

Table 2: Mass fractions of the components of kerosene sample K1 (in percent), inferred from the simplified version of Table 6 of [26. CN stands for carbon number, Par for paraffins, $\mathrm{Na} / \mathrm{Ol}$ for naphthenes/olefins, Alk for alkylbenzene, Napht for naphtobenzene, Dia for diaromatics.

\section{Description of the model}

The Discrete Component Model (DCM), based on the analytical solutions to the equations describing heat transfer and species diffusion processes in the liquid phase, together with the Robin boundary conditions at the surface of the droplets, is used in our analysis [10, 12]. Following [28], we assume that the liquid species diffusion coefficient can be estimated using the WilkeChang formula with molar mass assumed to be equal to the average molar mass of all species. The analysis of the processes in the gas phase is based on a simplified version of the well known model suggested by Abramzon and Sirignano (see [10] for the details). The vapour diffusion coefficient is calculated using the following formula assuming that the vapour can be approximated by the dominant component cycloundecane (see Table 2) [29]:

$$
D_{v}=\left(-0.04025+2.4907 \times 10^{-4} \times T+3.1411 \times 10^{-7} \times T^{2}\right) \times 10^{-4} \quad\left[\mathrm{~m}^{2} / \mathrm{s}\right],
$$

where $T$ is the gas reference temperature in $\mathrm{K}$.

Note that the Abramzon and Sirignano model is based on the assumption that the sum of vapour and air densities above the surface of the droplets 
is constant. This assumption is acceptable for the analysis of droplets suspended in relatively low temperature gas but becomes questionable in the case of high temperature gas. A more general model, free from this assumption, was developed in [30, 31]. The application of this model is beyond the scope of our paper.

The effect of thermal expansion was accounted for in our analysis following the approach described in [10]. Although, strictly speaking, this model is only applicable to the analysis of spherical droplets, its applicability can be extended to spheroidal droplets with eccentricities close to 1 . This follows from the analysis in [13] where it was shown that the evaporation times of spherical and spheroidal droplets, having the same volume, in conditions typical of Diesel engines, are reasonably close for eccentricities up to about 1.5 .

The Nusselt number for non-evaporating droplet heating based on the droplet diameter, taking into account the effects of natural convection, is estimated using the Churchill correlation [32]:

$$
\mathrm{Nu}_{\mathrm{ne}}=2+\frac{0.589 \mathrm{Ra}^{1 / 4}}{\left[1+(0.469 / \mathrm{Pr})^{9 / 16}\right]^{4 / 9}}
$$

where Ra and Pr are the Rayleigh and Prandtl numbers, respectively. This value is multiplied by $\ln \left(1+B_{T}\right) / B_{T}$, where $B_{T}$ is the Spalding heat transfer number [10]. The correlations required for $\mathrm{Nu}$ to take into account the effects of forced convection are discussed in [10].

The contribution of supporting fibre was taken into account following the approach suggested in [15]. This approach is in turn based on the analytical solution to the spherically symmetrical heat conduction equation inside the droplet in the presence of thermal radiation, assuming that the droplet is semi-transparent [10, 15]. Following [15], the total heat supplied to the droplet via the supporting fibre is identified using the total amount of thermal radiation supplied to the droplet, assuming that in both cases this heat is homogeneously distributed inside the droplet. This allowed us to apply 120 the analytical solution for the semi-transparent droplet heated by thermal radiation to the analysis of droplet heating via a supporting fibre (see [15] for a more detailed description of this approach). 


\section{Results}

The model described in the previous section was applied to the investigation of kerosene droplet heating/evaporation using some of the experiments described in 25]. The authors of that paper considered heating/evaporation of kerosene droplets in the range of diameters $0.9 \mathrm{~mm}$ to $1.1 \mathrm{~mm}$, with initial temperatures $298 \mathrm{~K}$, supported by $\mathrm{SiC}$ fibre of $100 \mu \mathrm{m}$ diameter. The ambient gas was at atmospheric pressure and temperatures were in the range $400^{\circ} \mathrm{C}$ to $800^{\circ} \mathrm{C}$. It was demonstrated in 25 that the experimental results obtained were compatible with those reported earlier in [33].

The comparison between the observed values of relative squared diameters of droplets $d^{2} / d_{0}^{2}$, where $d_{0}$ is the initial droplet diameter, versus normalised time $t / d_{0}^{2}$ and those predicted by the model for gas temperature $500^{\circ} \mathrm{C}$ is shown in Figure 1. This normalisation of time is used in this figure and some of the following figures to make it easier to compare the model predictions with experimental data for which the same normalisation of time was used. The following models were considered: the Discrete Component Model (DCM) taking into account the contributions of all kerosene components and the contributions of both natural convection and supporting fibre (plots $\mathrm{M}$ ); the DCM taking into account the contributions of all kerosene components and natural convection but not that of the supporting fibre (plots M1); the DCM taking into account the contributions of all kerosene components but not those of natural convection and the supporting fibre (plots M2). In all cases the kerosene composition shown in Table 1 was used. The thermodynamic and transport properties of the components used in our calculations are summarised in Section 1 of the Supplementary Material. Following [25], it was assumed that $d_{0}$ was equal to $1 \mathrm{~mm}$.

Following [15, in all these models it was assumed that the fibre temperature was equal to half the gas temperature measured in ${ }^{\circ} \mathrm{C}$. This assumption follows from the results of direct measurements of the fibre and gas temperatures in similar experiments with droplets suspended on fibre, as described in [15]. Thus, the fibre temperature was assumed equal to $250^{\circ} \mathrm{C}$ for gas temperature equal to $500^{\circ} \mathrm{C}$.

As follows from Figure 1, the predicted time dependence of $d^{2} / d_{0}^{2}$ is reasonably close to that observed experimentally, when the effects of both natural convection and support are taken into account. The effect of support is relatively small and can be ignored under the conditions of these experiments. At the same time ignoring the effect of natural convection leads to 
considerable over-estimation of the predicted droplet evaporation time.

The deviation between the predicted and experimental plots is something that we expected. There could be several reasons for this. Firstly, the kerosene composition which we used in our modelling is unlikely to be an exact match to the one used in the experiments (the composition of kerosene used in the original experiments is not known to us). Secondly, the model used in our analysis might be rather simplistic (e.g. observed non-sphericity of droplets was not taken into account). Thirdly, the errors in measurement of gas temperature, taken with a thermocouple, could exceed several percent $\left(8^{\circ} \mathrm{C}\right.$ for gas temperature $500^{\circ} \mathrm{C}$ [33]). Finally, droplet diameters could deviate from the $1 \mathrm{~mm}$ used in our calculations. To investigate the possible contribution of the latter effects, we produced plots similar to those shown in Figure 1 (plots M) but for initial droplet diameters equal to $0.9 \mathrm{~mm}$ and 1.1 $\mathrm{mm}$ (the lower and upper limits of the initial droplet diameters used in the experiments described in [25]). The results of comparisons between predicted values of $d^{2} / d_{0}^{2}$ for all three initial droplet diameters $(0.9 \mathrm{~mm}, 1 \mathrm{~mm}$ and 1.1 $\mathrm{mm}$ ) and experimental data are presented in Figure 2. As in the case of Fig. 1 , it was assumed that $d_{0}$ is equal to $1 \mathrm{~mm}$ for normalised time $t / d_{0}^{2}$.

As can be seen from this figure, the experimental curves lie between the predicted curves for droplet initial diameters $0.9 \mathrm{~mm}$ and $1.1 \mathrm{~mm}$. This gives us reasonable confidence in the reliability of the predictions of our model.

About the same level of agreement between the prediction of the model and experimental data as presented in Figures 1 and 2 was observed for gas temperature $600^{\circ} \mathrm{C}$ (the relevant plots are not shown in the paper). Plots similar to those presented in Figures 1 and 2 but for ambient gas temperature $700^{\circ} \mathrm{C}$ are shown in Figures 3 and 4 . As can be seen from Figure 3, the agreement between the predictions of the model and experimental data is visibly poorer for gas temperature $700^{\circ} \mathrm{C}$ than for gas temperature $500^{\circ} \mathrm{C}$. This could be linked to several factors, including the limitations of the gas phase model used in our analysis. One of the main assumptions of this model, that the density of the mixture of vapour and air does not depend on the distance from the droplet surface, might be marginally acceptable for gas temperature $500^{\circ} \mathrm{C}$ but is questionable for gas temperature $700^{\circ} \mathrm{C}$. As in the case of gas temperature $500^{\circ} \mathrm{C}$, the effect of support on droplet evaporation for gas temperature $700^{\circ} \mathrm{C}$ is predicted to be small, while the effect of natural convection cannot be ignored for this temperature as it could not be ignored for gas temperature $500^{\circ} \mathrm{C}$.

As can be seen from Figure 4, the experimental curves lie between the 
predicted curves for droplet initial diameters $0.9 \mathrm{~mm}$ and $1.1 \mathrm{~mm}$ for gas temperature $700^{\circ} \mathrm{C}$. This gives us reasonable confidence in the reliability of the predictions of our model for this gas temperature as well.

The observed evaporation times and those predicted by the models for ambient gas temperatures in the range $400^{\circ} \mathrm{C}$ to $800^{\circ} \mathrm{C}$ are presented in Table 3. To make comparison between the experimental and modelling results easier, we compared not the total evaporation times (which were not observed in the experiments in [25]), but the time instants when droplet diameters reached the minimal observable values. Both these time instants and the minimal observable droplet diameters for various ambient gas temperatures are shown in the second column of Table 3 .

\begin{tabular}{|c||c|c|c|c|}
\hline Temperature & Experiment [25] & M & M1 & M2 \\
\hline \hline $400^{\circ} \mathrm{C}$ & $0.127 \mathrm{~mm}, 6.540 \mathrm{~s}$ & $5.022 \mathrm{~s}$ & $5.093 \mathrm{~s}$ & $6.258 \mathrm{~s}$ \\
\hline $500^{\circ} \mathrm{C}$ & $0.134 \mathrm{~mm}, 3.989 \mathrm{~s}$ & $3.574 \mathrm{~s}$ & $3.658 \mathrm{~s}$ & $4.507 \mathrm{~s}$ \\
\hline $600^{\circ} \mathrm{C}$ & $0.169 \mathrm{~mm}, 2.587 \mathrm{~s}$ & $2.713 \mathrm{~s}$ & $2.791 \mathrm{~s}$ & $3.443 \mathrm{~s}$ \\
\hline $700^{\circ} \mathrm{C}$ & $0.172 \mathrm{~mm}, 1.920 \mathrm{~s}$ & $2.214 \mathrm{~s}$ & $2.282 \mathrm{~s}$ & $2.810 \mathrm{~s}$ \\
\hline $800^{\circ} \mathrm{C}$ & $0.199 \mathrm{~mm}, 1.308 \mathrm{~s}$ & $1.842 \mathrm{~s}$ & $1.901 \mathrm{~s}$ & $2.336 \mathrm{~s}$ \\
\hline
\end{tabular}

Table 3: Time instants when droplet diameters reached the minimal observable values for various ambient gas temperatures, as inferred from the experiments described in [25] (columns 1 and 2); corresponding time instants (evaporation times) predicted by models M, M1 and M2 (columns 3-5). Droplet diameters were taken equal to $1 \mathrm{~mm}$ in our calculations.

As can be seen from Table 3, the predicted evaporation times of droplets (model M) at ambient temperatures in the range $500^{\circ} \mathrm{C}$ to $700^{\circ} \mathrm{C}$ are rather close to those observed experimentally. It was shown that the experimentally observed times lie between the model M predictions for droplet diameters 0.9 $\mathrm{mm}$ and $1.1 \mathrm{~mm}$ for this range of temperatures.

At the same time, Table 3 shows that there are noticeable deviations between the model predictions and experimental data for ambient gas temperatures $400^{\circ} \mathrm{C}$ and $800^{\circ} \mathrm{C}$. Moreover, the experimentally observed times lie outside the model predictions for droplet diameters $0.9 \mathrm{~mm}$ and $1.1 \mathrm{~mm}$ for these temperatures. This lack of clear agreement between the experimental and modelling results for ambient gas temperature $800^{\circ} \mathrm{C}$ could be attributed to the limitations of the droplet evaporation model at high gas temperatures. The reasons for the lack of agreement at gas temperature $400^{\circ} \mathrm{C}$ are not clear 
to us. In what follows, our analysis will be focused on droplet heating and evaporation at ambient gas temperatures $500^{\circ} \mathrm{C}$ and $700^{\circ} \mathrm{C}$, as the limiting temperatures for which the model was validated.

225 $d^{2} / d_{0}^{2}$ versus normalised time $t / d_{0}^{2}$ predicted by the model for gas temperature $700^{\circ} \mathrm{C}$ (as in the case shown in Figures 3 and 4), and using input parameters presented in Tables 1 and 2, is shown in Figure 5. The curves are presented for 3 values of initial droplet diameter $(0.9 \mathrm{~mm}, 1 \mathrm{~mm}, 1.1 \mathrm{~mm})$. are rather close. This could potentially allow us to use either of these tables for the analysis of kerosene droplets, depending on the availability of the properties of the components.

Plots of the temperatures of the droplet surfaces versus time $t$ for the 235 shown in Figure 6. Two models were used for our analysis: the DCM taking into account the effects of support and natural convection (curves M); and the DCM ignoring these effects (curves M2). As can be seen from this figure, the values of droplet surface temperature are strong functions of the choice support and natural convection leads to prediction of higher droplet surface temperatures than when these effects are ignored. In all cases the predicted droplet surface temperatures increased with increasing ambient gas temperature, as expected. Note that the model used in our analysis is not expected 245 to be accurate at temperatures close to the boiling temperatures of the components (see [10] for the details). Also, the results of calculations at the very final stage of droplet evaporation, when droplet diameters approach zero, are not expected to be reliable. Hence, caution is needed when discussing the physical background of the temperatures at the final stages of evaporation shown in Figure 6.

The difference in droplet evaporation characteristics for gas temperatures between $500^{\circ} \mathrm{C}$ and $700^{\circ} \mathrm{C}$ could be attributed to different species compositions at the droplet surface during the evaporation for these temperatures. In our model, the rates of diffusion of different species are assumed to be 255 the same. The surface liquid mass fractions of selected kerosene components versus $t / d_{0}^{2}$ for initial droplet diameter $1 \mathrm{~mm}$ and gas temperature $700^{\circ} \mathrm{C}$ are presented in Figure 7 . As can be seen from this figure, the surface mass fraction of the least volatile component (cycloalkane C17) monotonically increases with time. Mass fractions of all other components shown in this 


\begin{tabular}{|c|c|c|c|c|}
\hline Surr. & $n-$ or iso-alkanes & Cycloalkanes & Alkylbenzene & Ind, Tet \& Naph \\
\hline 1 & $100 \%$ of $C_{10} H_{22}$ & 0 & 0 & 0 \\
\hline 2 & $57.6923 \%$ of $\mathrm{C}_{12} \mathrm{H}_{26}$ & $19.7436 \%$ of $\mathrm{C}_{7} \mathrm{H}_{14}$ & $22.5641 \%$ of $\mathrm{C}_{8} \mathrm{H}_{10}$ & 0 \\
\hline 3 & $46.4229 \%$ of $\mathrm{C}_{10} \mathrm{H}_{22}$ & $26.0095 \%$ of $\mathrm{C}_{10} \mathrm{H}_{20}$ & $27.5676 \%$ of $\mathrm{C}_{10} \mathrm{H}_{14}$ & 0 \\
\hline 4 & $30.8611 \%$ of $\mathrm{C}_{10} \mathrm{H}_{22}$ & $33.5642 \%$ of $\mathrm{C}_{10} \mathrm{H}_{20}$ & $35.5748 \%$ of $\mathrm{C}_{10} \mathrm{H}_{14}$ & 0 \\
\hline 5 & $76.9231 \%$ of $\mathrm{C}_{10} \mathrm{H}_{22}$ & 0 & $23.0769 \%$ of $\mathrm{C}_{6} \mathrm{H}_{6}$ & 0 \\
\hline 6 & $77.6398 \%$ of $\mathrm{C}_{12} \mathrm{H}_{26}$ & 0 & $22.3602 \%$ of $\mathrm{C}_{9} \mathrm{H}_{12}$ & 0 \\
\hline 7 & $\begin{array}{l}28.7613 \% \text { of } \mathrm{C}_{12} \mathrm{H}_{26} \\
19.5321 \% \text { of } \mathrm{C}_{14} \mathrm{H}_{30} \\
10.1368 \% \text { of } \mathbf{C}_{16} \mathbf{H}_{34}\end{array}$ & $\begin{array}{c}19.6855 \% \text { of } \mathrm{C}_{7} \mathrm{H}_{14} \\
15.6845 \% \text { of } \mathrm{C}_{10} \mathrm{H}_{20}\end{array}$ & 0 & $6.1997 \%$ of $\mathrm{C}_{10} \mathrm{H}_{12}$ \\
\hline 8 & $\begin{array}{r}40.1989 \% \text { of } \mathrm{C}_{12} \mathrm{H}_{26} \\
26.6884 \% \text { of } \mathbf{C}_{16} \mathbf{H}_{34}\end{array}$ & $14.3968 \%$ of $\mathrm{C}_{7} \mathrm{H}_{14}$ & 0 & $18.7159 \%$ of $\mathrm{C}_{11} \mathrm{H}_{10}$ \\
\hline 9 & $\begin{array}{c}9.1 \% \text { of } C_{6} H_{14} \\
72.7 \% \text { of } C_{10} H_{22}\end{array}$ & 0 & $18.2 \%$ of $\mathrm{C}_{6} \mathrm{H}_{6}$ & 0 \\
\hline 10 & $87.0841 \%$ of $C_{10} H_{22}$ & 0 & $12.9159 \%$ of $\mathrm{C}_{6} \mathrm{H}_{6}$ & 0 \\
\hline 11 & $\begin{array}{l}10.9974 \% \text { of } \mathbf{C}_{8} \mathbf{H}_{18} \\
18.3902 \% \text { of } C_{12} H_{26} \\
30.2090 \% \text { of } C_{16} H_{34}\end{array}$ & $9.7223 \%$ of $\mathrm{C}_{9} \mathrm{H}_{18}$ & 0 & $30.6811 \%$ of $\mathrm{C}_{11} \mathrm{H}_{10}$ \\
\hline 12 & $\begin{array}{l}28.1328 \% \text { of } C_{10} H_{22} \\
19.2691 \% \text { of } C_{12} H_{26} \\
15.2804 \% \text { of } \mathbf{C}_{16} \mathbf{H}_{34}\end{array}$ & $19.7829 \%$ of $\mathrm{C}_{7} \mathrm{H}_{14}$ & $11.3045 \%$ of $\mathrm{C}_{8} \mathrm{H}_{10}$ & $6.2303 \%$ of $\mathrm{C}_{10} \mathrm{H}_{12}$ \\
\hline 13 & $\begin{array}{l}18.6725 \% \text { of } \mathrm{C}_{10} \mathrm{H}_{22} \\
38.3681 \% \text { of } \mathrm{C}_{12} \mathrm{H}_{26}\end{array}$ & $26.1542 \%$ of $\mathrm{C}_{10} \mathrm{H}_{20}$ & $16.8052 \%$ of $\mathrm{C}_{6} \mathrm{H}_{6}$ & 0 \\
\hline
\end{tabular}

Table 4: Mass fractions of the components of kerosene surrogates (Surr.). 'Ind, Tet \& Naph' stands for indane and tetraline $\left(\mathrm{C}_{10} \mathrm{H}_{12}\right)$ or naphtalenes $\left(\mathrm{C}_{11} \mathrm{H}_{10}\right)$. n-alkanes are shown in italic, while iso-alkanes are shown in bold.

figure, except naphtobenzene $\mathrm{C} 12$, initially increase and then decrease with time. In the case of naphtobenzene $\mathrm{C} 12$ this mass fraction initially decreases with time, then increases and then decreases again until it fully evaporates. The composition of kerosene at the surface of the droplets at any given time instant appears to be rather different for each of the gas temperatures which we considered. The effects of this change in droplet composition on diffusion of kerosene vapour species cannot be easily accounted for by the models used in our analysis. The application of a more advanced gas phase model would be required in this case (see [34] for further details).

\section{Kerosene surrogates}

The composition of surrogates used in our analysis is presented in Table 4. while the names by which these surrogates are known and the references in which they are described are shown in Table 5. As can be seen from these tables, eleven surrogates taken from the literature and two original surrogates were used in our analysis. The number of components in these surrogates was between one and six.

In all cases, the selection of surrogates was based mainly on the similarity between the key properties of the surrogates and kerosene. These properties included molar mass, the ratio of the numbers of hydrogen and carbon atoms 


\begin{tabular}{|c||c|c|}
\hline Surr. & Known as & Refs. \\
\hline \hline 1 & Normal decane & {$[35,[36]$} \\
\hline 2 & Surrogate C & {$[37]$} \\
\hline 3 & Surrogate D & {$[38]$} \\
\hline 4 & Surrogate E & {$[38]$} \\
\hline 5 & Aachen surrogate & {$[39]$} \\
\hline 6 & Modified Aachen surrogate & {$[38]$} \\
\hline 7 & Modified Utah surrogate & {$[40]$} \\
\hline 8 & Drexel surrogate 2 & {$[38]$} \\
\hline 9 & Strelkova surrogate & {$[41]$} \\
\hline 10 & Lindstedt surrogate & {$[42]$} \\
\hline 11 & Slavinskaya surrogate & {$[43]$} \\
\hline 12 & SU1 & $\mathrm{O}$ \\
\hline 13 & SU2 & $\mathrm{O}$ \\
\hline
\end{tabular}

Table 5: Names by which surrogates mentioned in Table 4 are known and the references in which they are described. 'O' shows that these surrogates are those originally developed at Samara National Research University (see Section 5 for further details).

(H/C), basic composition, 1 ignition delay, laminar flame velocity, density, specific heat of evaporation, cetane number, viscosity, surface tension, distillation curve, and production of soot precursors ([45, 46, 47]). For example, n-decane (Surrogate 1) was selected due to its ability to reproduce the ignition temperature of kerosene [35, 36, 48, 49].

Surrogates C, D, and E, the Modified Aachen surrogate, Drexel surrogate 2 and the Slavinskaya surrogate (surrogates 2-4, 6, 8, 11) were selected based on the characteristics of flame extinction and the flame ignition temperature of kerosene [37, 38, 43. The Aachen surrogate (surrogate 5) was selected based on its ability to reproduce the ignition delay for various initial pressures and temperatures [39]. The modified Utah surrogate (surrogate 7) was selected for its ability to reproduce the distillation curve and the structure of the laminar flame of kerosene [40]. The Strelkova surrogate (surrogate 9) was selected for its ability to reproduce kerosene detonation characteristics 41].

\footnotetext{
${ }^{1}$ It was taken into account that the volume fractions of the components of kerosene include 50-65\% alkanes, 20-30\% cycloalkanes, and 10-20\% aromatics [44]
} 
The Lindstedt surrogate (surrogate 10) was selected based on its ability

to reproduce the oxidation of aromatics in kerosene. Mass fractions of CO and $\mathrm{CO}_{2}$ in kerosene and surrogates with various aromatics were compared. The selection of Slavinskaya surrogate (surrogate 11) also focused on the evaporation curve for kerosene ( $p-T$ diagram). Studies of individual components which could be potentially used as kerosene surrogates are described in [50, 51, 52].

As follows from this brief overview, in all cases the surrogates were selected based only on some of their properties. The investigation of other properties of these surrogates and the comparison of these properties with those of kerosene has still to be performed.

In contrast to most of the previously suggested surrogates, we took into account as many kerosene properties as possible when selecting surrogates SU1 and SU2 (surrogates 12 and 13). Our main focus was on the presence of key kerosene components in surrogates, closeness of surrogate and kerosene densities, H/C ratios, molar masses and the stoichiometric coefficients of surrogates and kerosene. We aimed to achieve deviations between these parameters for surrogates and kerosene not exceeding $4 \%$ for molar mass, ${ }^{2} 2 \%$ for $\mathrm{H} / \mathrm{C}$ ratios, and $1 \%$ for densities. The deviations between the experimentally observed mass fractions of combustion products $\left(\mathrm{O}_{2}, \mathrm{~N}_{2}, \mathrm{CO}_{2}, \mathrm{H}_{2} \mathrm{O}\right)$ for these surrogates and kerosene did not exceed the experimental errors (around $5 \%$ ). For $\mathrm{CO}_{2}$ the average deviation for $\mathrm{SU} 1$ (SU2) was shown to be $1.33 \%$ $(1.27 \%)$ and the maximal deviation for these surrogates was shown to be $2.34 \%(1.77 \%)$. For $\mathrm{H}_{2} \mathrm{O}$ the average deviation for $\mathrm{SU} 1$ (SU2) was $0.71 \%$ $(1.07 \%)$ and the maximal deviation for these surrogates was shown to be $1.86 \%(2.35 \%)$. These deviations were much smaller than those for surrogate $\mathrm{C}$ (surrogate 2 in Table 2) for which the average (maximal) deviation for $\mathrm{CO}_{2}$ was $4.19 \%(6.51 \%)$ and $7.87 \%(8.72 \%)$ for $\mathrm{H}_{2} \mathrm{O}[53]$.

For CO the deviation for SU1 (SU2) and kerosene did not exceed 5.3\% $(10.7 \%)$, with average deviation $3.5 \%$ (5.6\%). For hydrocarbons (HC) the deviation for SU1 (SU2) and kerosene did not exceed 12.2\% (10.4\%), with average deviation $10.7 \%(6.3 \%)$. As in the case of $\mathrm{CO}_{2}$ and $\mathrm{H}_{2} \mathrm{O}$, these deviations were much smaller than those for surrogate $\mathrm{C}$ for which the average (maximal) deviation for $\mathrm{CO}$ was $5.7 \%(7.6 \%)$ and $5.1 \%(6.0 \%)$ for $\mathrm{HC}$ [53]. These results show clear advantages of surrogates SU1 and SU2 compared

\footnotetext{
${ }^{2}$ A similar approach was used to select surrogate C (surrogate 2).
} 
with surrogate C.

When selecting between SU1 and SU2 (surrogates 12 and 13), preference tends to be given to SU2. This surrogate contains fewer components than SU1 and is easier to use in calculations. At the same time the deviations between mass fractions of $\mathrm{CO}$ observed for SU1 and those for kerosene are less than the corresponding deviations for SU2 and kerosene. Although SU2 contains fewer components than SU1, the cost of SU2 components is higher than that of SU1 components. Hence, the final selection between SU1 and SU2 has still to be made.

Approximations of the transport and thermodynamic properties of the components used in the above-mentioned surrogates are presented in Section 2 of the Supplementary Material. The kerosene composition shown in Table 1 was used in our analysis.

\section{Analysis}

The heating/evaporation characteristics of droplets of the surrogate fuels shown in Tables 4 and 5 were compared with those of kerosene, with a composition as shown in Table 1, for the same conditions as described in Section 4 for fibre supported droplets at atmospheric pressure and temperatures $500^{\circ} \mathrm{C}$ and $700^{\circ} \mathrm{C}$. The surrogates shown in these tables were divided into 2 groups: one with decane as the main component or one of the main components (Group 1) and another with dodecane as the main component or one of the main components (Group 2).

The plots of normalised droplet diameters versus time divided by the initial droplet diameter squared for kerosene and kerosene surrogates are shown in Fig. 8. The droplet is assumed to be heated and evaporating in air at atmospheric pressure and temperature $500^{\circ} \mathrm{C}$. The results for surrogates of Group 1 are shown in Fig. 8a, while those for surrogates of Group 2 are shown in Fig. 8b. The same plots as in Fig. 8 but for gas temperature $700^{\circ} \mathrm{C}$ are shown in Fig. 9. Zoomed parts of the plots shown in Fig. 9 are presented in Figs. 10 and 11.

As follows from Figs. 8a, 9a, 10a and 11a, the evaporation characteristics of droplets of surrogate SU1 (surrogate 12) are the closest to those of kerosene among the surrogates of Group 1 (decane dominated surrogates) for both gas temperatures. The evaporation of all other surrogates in Group 1 is noticeably slower than that of kerosene. 
As follows from Figs. 8b, 9b, 10b and 11b, the evaporation characteristics of droplets of the modified Utah surrogate (surrogate 7) are the closest to those of kerosene among the surrogates of Group 2 (dodecane dominated surrogates) for both gas temperatures. The droplets of Drexel surrogate 2 (surrogate 8) and Slavinskaya surrogate (surrogate 11) of this group evaporate more slowly than kerosene droplets, while droplets of all other surrogates of this group evaporate more quickly than kerosene droplets.

Plots of relative evaporation times $\tau=\left[\left(t_{e((\mathrm{~K})}-t_{e(\mathrm{~S})}\right) / t_{e(\mathrm{~K})}\right] \times 100 \%$ versus surrogate numbers for both ambient temperatures are shown in Fig. 12. Since calculation of $t_{e((\mathrm{~K})}$ and $t_{e((\mathrm{~S})}$ at the time instants when droplet radii was equal to 0 were not possible, these times were estimated for the time instants when droplet radii reached their minimal values (the same for kerosene and surrogates) (cf. Table 3). As one can see from this figure, the minimal absolute values of $\tau$ are predicted for Surrogates 7 (modified Utah surrogate) and 12 (SU1). In most cases, $\tau$ is negative, which shows that kerosene droplets tend to evaporate faster than surrogate droplets. The values of $\tau$ for both temperatures are rather close in most cases. All these results are consistent with those inferred from Figs. 8-11.

Plots similar to those presented in Figs. 8 and 9 but for droplet surface temperatures are shown in Figs. 13 and 14. Zoomed parts of the plots shown in Fig. 14 are presented in Fig. 15. As can be seen from Figs. 13a, 14a and 15a, among surrogates of Group 1, the heating characteristics of droplets of SU1 (surrogate 12) are closest to those of kerosene droplets, as in the case of droplet evaporation.

From Figs. 13b, 14b and 15b it follows that among surrogates of Group 2 , the heating characteristics of droplets of surrogate 7 (modified Utah surrogate) are closest to those of kerosene droplets, as in the case of droplet evaporation. The heating characteristics of droplets of surrogates 8 and 11 (Drexel surrogate 2 and Slavinskaya surrogate) are also reasonably close to those of kerosene droplets. The heating characteristics of droplets of other surrogates from both groups turned out to be rather different from those of kerosene droplets, especially at the late stage of droplet heating and evaporation.

Considering the balance between the heating and evaporation characteristics of droplets of 13 surrogates considered in the paper we can conclude that those of SU1 and the modified Utah surrogate are the closest to those of kerosene droplets. The characteristics of droplets of Drexel surrogate 2 and Slavinskaya surrogate are also reasonably close to those of kerosene droplets, 
although droplets of these surrogates show slightly longer evaporation times compared with those for kerosene droplets. The characteristics of droplets of other surrogates are rather different from those of kerosene droplets. The approximation of kerosene droplets by droplets of these surrogates is likely to introduce considerable errors to the prediction of their droplet heating and evaporation parameters.

\section{Conclusion}

A Discrete Component Model (DCM) was applied to the investigation of heating/evaporation of suspended kerosene droplets. The composition of kerosene with 57 components was taken from [26]. This composition was simplified to 40 components. In the simplified composition, the contributions of n-paraffins and iso-paraffins were not distinguished as the contributions of mono-, di- and tri-naphthenes/olefins, and naphthalenes. Biphenyls and fluorenes were treated as the same substances as diaromatics. This was justified by the closeness of the thermodynamic and transport properties of these components. The heating/evaporation characteristics of droplets with original and simplified kerosene compositions were shown to be close.

The effect of natural convection was taken into account using the Churchill approximation, while effects due to the supporting fibre were modelled using a simplified approach based on the assumption that additional heat supplied via the fibre is uniformly distributed within the droplet volume. This droplet heating via the supporting fibre was modelled using the mathematical tools previously developed for radiative heating of semi-transparent droplets.

It was shown that the effect of supporting fibre can be ignored for this experiment but not the effect of natural convection. The time evolution of droplet radii predicted by the DCM, taking into account the effects of natural convection and supporting fibre, is shown to be close to experimental predictions of this parameter by [25] for gas temperatures in the range $500^{\circ} \mathrm{C}$ 430 to $700^{\circ} \mathrm{C}$.

Heating/evaporation characteristics of droplets of 11 previously reported and 2 original kerosene surrogates, inferred mainly from the analysis of their ignition/combustion properties, were compared with those of kerosene droplets. These characteristics were studied based on the analysis of heating and evaporation of suspended droplets in air at atmospheric pressure and temperatures $500^{\circ} \mathrm{C}$ and $700^{\circ} \mathrm{C}$. Kerosene compositions taken from [26] were used in our analysis. 
Considering the balance between the heating and evaporation characteristics of droplets we concluded that those of original surrogate SU1 and the modified Utah surrogate [40] are the closest to those of kerosene droplets. The characteristics of droplets of Drexel surrogate 2 [38] and Slavinskaya surrogate [43] were shown to be reasonably close to those of kerosene droplets, although droplets of these surrogates take slightly longer to evaporate than kerosene droplets. The characteristics of droplets of other surrogates were shown to be rather different from those of kerosene droplets.

\section{Acknowledgements}

This work was supported by the Engineering and Physical Sciences Research Council (UK) [EPSRC Studentship 1792531 and grants EP/M002608/1 and EP/R012024/1], the Russian Science Foundation (project No. 19-7900325) the Royal Society (project 192007) and the Institute of Space Technology of Pakistan (53201/IST/2017/1). The UK Fluids network is gratefully acknowledged for its support of the Special Interest Group 'Sprays in engineering applications: modelling and experimental studies'. This group was a platform for the exchange of ideas between researchers working on various aspects of spray research. This paper originated in part as a result of this exchange of ideas.

\section{References}

[1] Y. Yan, Y. Liu, D. Di, C. Dai, J. Li, Simplified chemical reaction mechanism for surrogate fuel of aviation kerosene and its verification, Energy \& Fuels 30 (12) (2016) 10847-10857. doi:10.1021/acs.energyfuels . 6b01852.

URL https://doi .org/10.1021/acs . energyfuels.6b01852

[2] V. Alekseev, J. Soloviova-Sokolova, S. Matveev, I. Chechet, S. Matveev, A. Konnov, Laminar burning velocities of n-decane and binary kerosene surrogate mixture, Fuel 187 (2017) 429 - 434. doi:https://doi.org/10.1016/j.fuel.2016.09.085. URL http://www.sciencedirect.com/science/article/pii/ S0016236116309486

[3] Y. Yan, Y. Liu, W. Fang, Y. Liu, J. Li, A simplified chemi470 cal reaction mechanism for two-component RP-3 kerosene surrogate fuel and its verification, Fuel 227 (2018) 127 - 134. 
doi:https://doi.org/10.1016/j.fuel.2018.04.092.

475 [4] X. Fang, Z. Huang, X. Qiao, D. Ju, X. Bai, Skeletal mechanism development for a 3-component jet fuel surrogate using semi-global sub-mechanism construction and mechanism reduction, Fuel 229 (2018) 53 - 59. doi:https://doi.org/10.1016/j.fuel.2018.04.159.

480

$$
\text { URL http://www.sciencedirect.com/science/article/pii/ }
$$
S0016236118307968

[5] D. Kim, A. Violi, Hydrocarbons for the next generation of jet fuel surrogates, Fuel 228 (2018) 438 - 444. doi:https: //doi.org/10.1016/j.fuel.2018.04.112.
URL http://www.sciencedirect.com/science/article/pii/ S0016236118307452

[6] Y. Liu, Y. Liu, D. Chen, W. Fang, J. Li, Y. Yan, A simplified mechanistic model of three-component surrogate fuels for RP-3 aviation kerosene, Energy \& Fuels 32 (9) (2018) 9949-9960. doi:10.1021/acs. energyfuels.8b02094.

URL https://doi.org/10.1021/acs .energyfuels .8b02094

[7] Y. Wu, V. Modica, X. Yu, F. Grisch, Experimental investigation of laminar flame speed measurement for kerosene fuels: Jet A-1 surrogate fuel, and its pure components, Energy \& Fuels 32 (2018) 2332-2343.

[8] T. J. Bruno, M. L. Huber, Evaluation of the physicochemical authenticity of aviation kerosene surrogate mixtures. part 2: Analysis and prediction of thermophysical properties, Energy \& Fuels 24 (8) (2010) 4277-4284. arXiv:https://doi.org/10.1021/ef1004978, http://dx.doi.org/10.1021/ef1004978 doi : 10.1021/ef 1004978. URL https://doi.org/10.1021/ef1004978

[9] X. Chen, E. Khani, C. Chen, A unified jet fuel surrogate for droplet evaporation and ignition, Fuel 182 (2016) 284 - 291. doi:https://doi.org/10.1016/j.fuel.2016.05.114. URL http://wwW.sciencedirect.com/science/article/pii/ S0016236116304355 


\section{[11]}

[13] V. S. Zubkov, G. E. Cossali, S. Tonini, O. Rybdylova, C. Crua, M. Heikal, S. S. Sazhin, Mathematical modelling of heating and evaporation of a spheroidal droplet, International Journal of Heat and Mass Transfer 108 (2017) 2181 - 2190. http://dx.doi.org/https://doi.org/10.1016/j.ijheatmasstransfer.2016.12.074 doi:https://doi.org/10.1016/j.ijheatmasstransfer.2016.12. 074. S001793101633438X

[14] S. S. Sazhin, O. Rybdylova, A. S. Pannala, S. Somavarapu, S. K. Zaripov, A new model for a drying droplet, International Journal of Heat and Mass Transfer 122 (2018) 451 - 458.

[15] P. A. Strizhak, R. S. Volkov, G. Castanet, F. Lemoine, O. Rybdylova, S. S. Sazhin, Heating and evaporation of suspended water droplets: Experimental studies and modelling, International Journal of Heat and Mass Transfer 127 (2018) 92 - 106. 
http://dx.doi.org/https://doi.org/10.1016/j.ijheatmasstransfer.2018.06.103 doi:https://doi.org/10.1016/j.ijheatmasstransfer.2018.06. 103. URL http://wWW.sciencedirect.com/science/article/pii/ S0017931018323056

6] O. Rybdylova, M. A. Qubeissi, M. Braun, C. Crua, J. Manin, L. M. Pickett, G. de Sercey, E. M. Sazhina, S. S. Sazhin, M. Heikal, A model for droplet heating and its implementation into ANSYS Fluent, International Communications in Heat and Mass Transfer 76 (2016) 265-270. http://dx.doi.org/http://dx.doi.org/10.1016/j.icheatmasstransfer.2016.05.032 doi:http://dx.doi.org/10.1016/j.icheatmasstransfer.2016.05. 032 .

URL http://www.sciencedirect.com/science/article/pii/ S0735193316301701

17] O. Rybdylova, L. Poulton, M. A. Qubeissi, A. E. Elwardany, C. Crua, T. Khan, S. S. Sazhin, A model for multi-component droplet heating and evaporation and its implementation into ANSYS Fluent, International Communications in Heat and Mass Transfer 90 (2018) 29 - 33. http://dx.doi.org/https://doi.org/10.1016/j.icheatmasstransfer.2017.10.018 doi:https://doi.org/10.1016/j . icheatmasstransfer.2017.10. 018 .

URL http://www.sciencedirect.com/science/article/pii/ S0735193317302816

[18] S. Siouris, S. Blakey, C. W. Wilson, Investigation of deposition in aviation gas turbine fuel nozzles by coupling of experimental data and heat transfer calculations, Fuel 106 (2013) $79-87$. doi:https://doi.org/10.1016/j.fuel.2012.12.006. URL http://wWW.sciencedirect.com/science/article/pii/ S0016236112010290

19] D. Yang, Z. Xia, L. Huang, L. Ma, Y. Feng, Y. Xiao, Exprimental study on the evaporation characteristics of the kerosene gel droplet, Experimental Thermal and Fluid Science 93 (2018) 171 - 177. http://dx.doi.org/https://doi.org/10.1016/j.expthermflusci.2017.12.031 doi :https://doi.org/10.1016/j .expthermflusci.2017.12.031. 
URL http://www.sciencedirect.com/science/article/pii/ S0894177717304260

575 [20] D. M. Kim, S. W. Baek, J. Yoon, Ignition characteristics of kerosene droplets with the addition of aluminum nanoparticles at elevated temperature and pressure, Combustion and Flame 173 (2016) 106 - 113. http://dx.doi.org/https://doi.org/10.1016/j.combustflame.2016.07.033 doi:https://doi.org/10.1016/j.combustflame.2016.07.033. URL http://www.sciencedirect.com/science/article/pii/ S0010218016301973

[21] M. N. Bello, K. J. Hill, M. L. Pantoya, R. J. Jouet, J. M. Horn, Surface engineered nanoparticles dispersed in kerosene: The effect of oleophobicity on droplet combustion, Combustion and Flame 188 (2018) $243-249$. http://dx.doi.org/https://doi.org/10.1016/j.combustflame.2017.09.041 doi:https://doi.org/10.1016/j.combustflame.2017.09.041. URL http://www.sciencedirect.com/science/article/pii/ S0010218017303796

[22] S. Yang, T. Hsu, M. Wu, Spray combustion characteristics of kerosene/bio-oil Part II: Numerical study, Energy 115 (2016) 458 467. http://dx.doi.org/https://doi.org/10.1016/j.energy.2016.09.047 doi:https://doi.org/10.1016/j.energy.2016.09.047. URL http://www.sciencedirect.com/science/article/pii/ S0360544216312828

595 [23] Z. Ren, B. Wang, G. Xiang, L. Zheng, Numerical analysis of wedgeinduced oblique detonations in two-phase kerosene/air mixtures, Proceedings of the Combustion Institute 37 (3) (2019) 3627 - 3635. doi:https://doi.org/10.1016/j.proci.2018.08.038. URL http://www.sciencedirect.com/science/article/pii/ S1540748918305807

[24] A. Giusti, M. Sitte, G. Borghesi, E. Mastorakos, Numerical investigation of kerosene single droplet ignition at high-altitude relight conditions, Fuel 225 (2018) $663-670$. doi:https: //doi.org/10.1016/j.fuel.2018.02.102.

605 URL http://www.sciencedirect.com/science/article/pii/ S0016236118302849 
[25] I. Javed, S. W. Baek, K. Waheed, G. Ali, S. O. Cho, Evaporation characteristics of kerosene droplets with dilute concentrations of ligand-protected aluminum nanoparticles at elevated temperatures, Combustion and Flame $160 \quad(12) \quad(2013) 2955$ - 2963. http://dx.doi.org/https://doi.org/10.1016/j.combustflame.2013.07.007 doi:https://doi.org/10.1016/j.combustflame.2013.07.007. URL http://www.sciencedirect.com/science/article/pii/ S0010218013002654

615 [26] K. Lissitsyna, S. Huertas, L. C. Quintero, L. M. Polo, PIONA analysis of kerosene by comprehensive two-dimensional gas chromatography coupled to time of flight mass spectrometry, Fuel 116 (2014) $716-722$. doi:https://doi.org/10.1016/j.fuel.2013.07.077.

http://www.sciencedirect.com/science/article/pii/ S0016236113006765

[27] J. A. Kent, T. Bommaraju, S. Barnicki, (Eds.), Handbook of Industrial Chemistry and Biotechnology, Springer-Verlag London, 2017.

[28] S. S. Sazhin, M. Al Qubeissi, R. Nasiri, V. Gun'ko, A. E. Elwardany, F. Lemoine, F. Grisch, M. R. Heikal, A multi625 dimensional quasi-discrete model for the analysis of diesel fuel droplet heating and evaporation, Fuel 129 (2014) 238 - 266. doi:https://doi.org/10.1016/j.fuel.2014.03.028.

1 URL http://www.sciencedirect.com/science/article/pii/ S0016236114002695

[29] C. Yaws, (Eds.), Thermophysical properties of chemicals and hydrocarbons, William Andrew, Norwich, NY, 2008.

[30] S. Tonini, G. E. Cossali, A novel vaporisation model for a single-component drop in high temperature air streams, International Journal of Thermal Sciences 75 (2014) 194 - 203. http://dx.doi.org/https://doi.org/10.1016/j.ijthermalsci.2013.08.004 doi:https://doi.org/10.1016/j.ijthermalsci.2013.08.004.

1. URL http://www.sciencedirect.com/science/article/pii/ S1290072913001932

[31] G. Cossali, S. Tonini, An analytical model of heat and 640 mass transfer from liquid drops with temperature depen- 
dence of gas thermo-physical properties, International Journal of Heat and Mass Transfer 138 (2019) 1166 - 1177. http://dx.doi.org/https://doi.org/10.1016/j.ijheatmasstransfer.2019.04.066 doi:https://doi.org/10.1016/j.ijheatmasstransfer.2019.04. 066.

URL http://www.sciencedirect.com/science/article/pii/ S0017931018363439

[32] S. W. Churchill, Free convection around immersed bodies, in: Heat Exchanger Design Handbook (Editor-in-Chief E.U. Schlünder), Hemisphere Publishing, New York, Section 2.5.7 1983.

[33] H. Ghassemi, S. W. Baek, Q. S. Khan, Experimental study on evaporation of kerosene droplets at elevated pressures and temperatures, Combustion Science and Technology 178 (2006) 1669-1684. doi:https: //doi.org/10.1080/00102200600582392.

[34] S. Tonini, G. E. Cossali, A multi-component drop evaporation model based on analytical solution of Stefan-Maxwell equations, International Journal of Heat and Mass Transfer 92 (2016) $184-189$. http://dx.doi.org/https://doi.org/10.1016/j.ijheatmasstransfer.2015.08.014 doi:https://doi.org/10.1016/j.ijheatmasstransfer.2015.08.

660 014.

URL http://wwW.sciencedirect.com/science/article/pii/ S0017931015301551

[35] P. Dagaut, M. Reuillon, M. Cathonnet, D. Voisin, High pressure oxidation of normal decane and kerosene in dilute conditions from low to high temperature, Twenty-Fifth Symposium (International) on Combustion / The Combustion Institute 92 (1995) 47-76.

[36] P. Dagaut, M. Reuillon, J. Boettner, M. Cathonnet, Kerosene combustion at pressures up to 40 atm: experimental study and detailed chemical kinetic modeling, Phys. Chem. Bio. 25 (1994) 919 - 926.

[37] S. Humer, A. Frassoldati, S. Granata, T. Faravelli, E. Ranzi, R. Seiser, Experimental and kinetic modeling study of combustion of JP-8, its surrogates and reference components in laminar nonpremixed flows, Proceedings of the Combustion Institute 31 (1) (2007) 393-400. 
[38] M. Colket, T. Edwards, S. Williams, . P. Cernansky, D. L. Miller, F. Egolfopoulos, P. Lindstedt, Development of an experimental database and kinetic models for surrogate jet fuels, in: 45th AIAA Aerospace Sciences Meeting and Exhibit, no. 770, American Institute of Aeronautics and Astronautics, 2007, pp. 1-21.

[39] A. Dean, O. Penyazkov, K. Sevruk, B. Varatharajan, Autoignition of surrogate fuels at elevated temperatures and pressures, Proceedings of the Combustion Institute 31 (2) (2007) 2481-2488.

[40] A. Violi, S. Yan, E. Eddings, A. Sarofim, S. Granata, T. Faravelli, E. Ranzi, Experimental formulation and kinetic model for JP-8 surrogate mixtures, Combustion Science and Technology 174 (11-12) (2002) 399-417.

[41] M. Strelkova, I. Kirillov, B. Potapkin, A. Safonov, L. Sukhanov, S. Umanskiy, M. Deminsky, A. Dean, B. Varatharajan, A. Tentner, Detailed and reduced mechanisms of jet a combustion at high temperatures, Combustion Science and Technology 180 (10) (2008) 1788 - 1802.

[42] R. Lindstedt, L. Maurice, Detailed chemical-kinetic model for aviation fuels, J. Propulsion and Power 16 (2) (2000) 187-195.

[43] N. A. Slavinskaya, A. Zizin, M. Aigner, On model design of a surrogate fuel formulation, Journal of Engineering for Gas Turbines and Power 132 (111501) (2010) 1-11.

[44] P. Dagaut, M. Cathonnet, The ignition, oxidation, and combustion of kerosene: A review of experimental and kinetic modeling, Progress in Energy and Combustion Science 32 (2006) 48-92.

[45] D. Kim, J. Martz, A. Violi, A surrogate for emulating the physical and chemical properties of conventional jet fuel, Combustion and Flame 161 (6) (2014) 1489 - 1498. http://dx.doi.org/https://doi.org/10.1016/j.combustflame.2013.12.015 doi:https://doi.org/10.1016/j.combustflame.2013.12.015.

[ URL http://www.sciencedirect.com/science/article/pii/ S001021801300463X

705 [46] J. A. Cooke, M. Bellucci, M. D. Smooke, A. Gomez, A. Violi, a T. Faravelli, E. Ranzi, Computational and experimental study of 
JP-8, a surrogate, and its components in counterflow diffusion flames, Proceedings of the Combustion Institute 30 (1) (2005) $439-446$. doi:https://doi.org/10.1016/j.proci.2004.08.046.

710 URL http://wwW.sciencedirect.com/science/article/pii/ S0082078404000992

[47] H. R. Zhang, E. G. Eddings, A. F. Sarofim, Criteria for selection of components for surrogates of natural gas and transportation fuels, Proceedings of the Combustion Institute 31 (1) (2007) $401-409$. doi:https://doi.org/10.1016/j.proci.2006.08.001.

\URL http://www.sciencedirect.com/science/article/pii/ S1540748906002641

[48] V. Alekseev, J. Soloviova-Sokolova, S. Matveev, I. Chechet, S. Matveev, A. Konnov, Laminar burning velocities of n-decane and binary kerosene surrogate mixture, Fuel 187 (2017) 429 - 434. doi:https://doi.org/10.1016/j.fuel.2016.09.085. URL http://www.sciencedirect.com/science/article/pii/ S0016236116309486

[49] S. Matveev, I. Chechet, A. Semenikhin, V. Abrashkin, S. Lukachev, S. Matveev, Experimental study of the combustion of kerosene and binary surrogate in the model combustion chamber, Journal of Combustion 2017 (2017) 3963075. doi:10.1155/2017/3963075.

[50] V. A. Alekseev, S. S. Matveev, I. V. Chechet, S. G. Matveev, A. A. Konnov, Laminar burning velocities of methylcyclohexane+air flames at room and elevated temperatures: A comparative study, Combustion and Flame $196 \quad$ (2018) $99-107$. http://dx.doi.org/https://doi.org/10.1016/j.combustflame.2018.06.010 doi:https://doi.org/10.1016/j.combustflame.2018.06.010. URL http://wWW.sciencedirect.com/science/article/pii/ [ S0010218018302451

[51] S. S. Matveev, D. V. Idrisov, S. G. Matveev, A. A. Konnov, Laminar burning velocities of surrogate components blended with ethanol, Combustion and Flame 209 (2019) 389 - 393. http://dx.doi.org/https://doi.org/10.1016/j.combustflame.2019.08.010 doi:https://doi.org/10.1016/j.combustflame.2019.08.010. 
1. URL http://www.sciencedirect.com/science/article/pii/ S0010218019303736

[52] J. S. . Sokolova, V. Alekseev, S. Matveev, I. Chechet, S. Matveev, - A. Konnov, Laminar burning velocities of benzene+air flames 745 at room and elevated temperatures, Fuel 175 (2016) $302-309$. doi:https://doi.org/10.1016/j.fuel.2016.02.054. URL http://www.sciencedirect.com/science/article/pii/ S0016236116001824

[53] E. A. Schepakina, S. G. Matveev, Development and Validation of a Combined Method and Algorithm for Calculating Pollutant Emission of a Combustion Chamber using Kerosene Surrogates, Samara University, 2018. 


\section{Figure Captions}

755

\section{Figure 1}

The plots of relative squared diameters of droplets $d^{2} / d_{0}^{2}$ versus $t / d_{0}^{2}$ predicted by the model discussed in Section 3 for ambient gas temperature equal to $500^{\circ} \mathrm{C}$ and using the kerosene composition shown in Table 1 . Curve $\mathrm{M}$ shows the prediction of the Discrete Component Model (DCM) taking into account the effect of supporting fibre and natural convection. Curves M1 and M2 show the prediction of the same model when the effects of support and support/natural convection are not taken into account. The droplet initial diameter $d_{0}$ was taken equal to $1 \mathrm{~mm}$. The experimental results are shown by circles.

\section{Figure 2}

The same as Figure 1 but for initial droplet diameters $0.9 \mathrm{~mm}, 1 \mathrm{~mm}$ and $1.1 \mathrm{~mm}$ (indicated near the curves). $d_{0}$ is taken equal to $1 \mathrm{~mm}$ in $t / d_{0}^{2}$. The contributions of both natural convection and supporting fibre were taken into account in all cases.

\section{Figure 3}

The same as Figure 1 but for ambient gas temperature equal to $700^{\circ} \mathrm{C}$.

$75 \quad$ Figure 4

The same as Figure 2 but for ambient gas temperature equal to $700^{\circ} \mathrm{C}$.

\section{Figure 5}

The same as Figure 4 but for kerosene compositions presented in Tables 1 and 2 (T1 and T2) and initial droplet diameters $0.9 \mathrm{~mm}, 1 \mathrm{~mm}$ and 1.1 $\mathrm{mm}$ (indicated near the curves). $d_{0}$ is taken equal to $1 \mathrm{~mm}$ in $t / d_{0}^{2}$.

\section{Figure 6}

The droplet surface temperature (in $\mathrm{K}$ ) versus time $t$ predicted by the same models as in Figs. 1-5 and for ambient gas temperatures equal to $500^{\circ} \mathrm{C}$ and $700^{\circ} \mathrm{C}$. The cases when the effects of both support and natural convection are taken into account (curves M) and ignored (curves M2) are shown. 


\section{Figure 7}

790 versus time $t$ predicted by the DCM taking into account both natural convection and supporting fibre for gas temperature $700^{\circ} \mathrm{C}$. The numbers after ' $\mathrm{C}$ ' are the carbon numbers, 'a' refers to n-alkane, 'ia' refers to iso-alkane, 'c' refers to cycloalkane, 'ic' refers to iso-cycloalkane, 'ab' refers to alkylbenzene, 795 the axes. $Y_{l s}$ for $\mathrm{C} 17 \mathrm{c}$ (the least volatile component) monotonically increases with time and reaches 1 just before the droplet evaporates completely. $Y_{l s}$ for C16ia reaches its maximal value of 0.349 when $t / d_{0}^{2}=3.5402 \mathrm{~s} / \mathrm{mm}^{2}$.

\section{Figure 8}

(a) Plots of normalised droplet diameters $\left(d^{2} / d_{0}^{2}\right)$ versus $t / d_{0}^{2}\left(\right.$ in $\left.\mathrm{s} / \mathrm{mm}^{2}\right)$ for kerosene (curve $\mathrm{K}$ ) and Group 1 kerosene surrogate (decane dominated) droplets heated and evaporating in air at atmospheric pressure and temperature $500^{\circ} \mathrm{C}$. Numbers near the curves refer to the numbers of surrogates given in Tables 4 and 5. (b) the same as (a) but for Group 2 kerosene surrogate (dodecane dominated) droplets.

\section{Figure 9}

The same as Figure 8 but for gas temperature $700^{\circ} \mathrm{C}$.

\section{Figure 10}

Zoomed parts of Figures 9a,b.

\section{Figure 11}

Zoomed parts of Figures 9a,b.

\section{Figure 12}

Plots of $\tau=\left(t_{e((\mathrm{~K})}-t_{e((\mathrm{~S})}\right) / t_{e((\mathrm{~K})}$ (in percent) versus surrogate number. $e$ refers to the evaporation time, $\mathrm{K}$ and $\mathrm{S}$ refer to kerosene and surrogates, respectively. Circles and triangles refer to the cases when the ambient gas

temperatures are equal to $500^{\circ} \mathrm{C}$ and $700^{\circ} \mathrm{C}$, respectively. 


\section{Figure 13}

The surface temperature versus time $t / d_{0}^{2}$ predicted by the same models 825 as shown in Figure 8. Plots (a) and (b) refer to the results for surrogates of Groups 1 and 2, respectively.

\section{Figure 14}

The surface temperature versus time $t / d_{0}^{2}$ predicted by the same models 830 as shown in Figure 9. Plots (a) and (b) refer to the results for surrogates of Groups 1 and 2, respectively.

\section{Figure 15}

Zoomed parts of Figures 14a,b. 


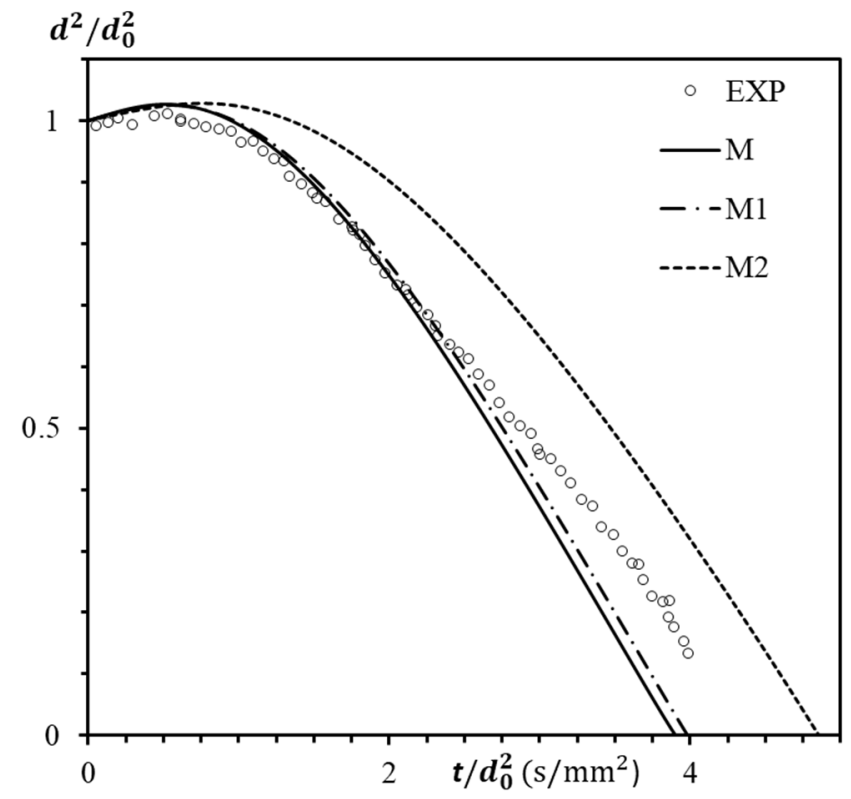

Fig. 1

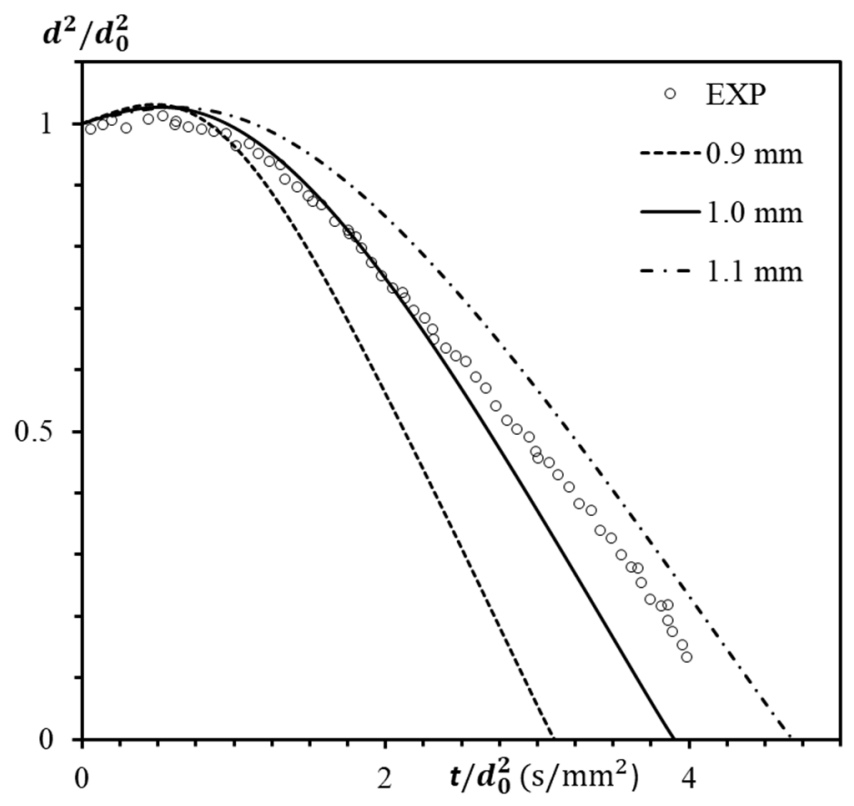

Fig. 2 


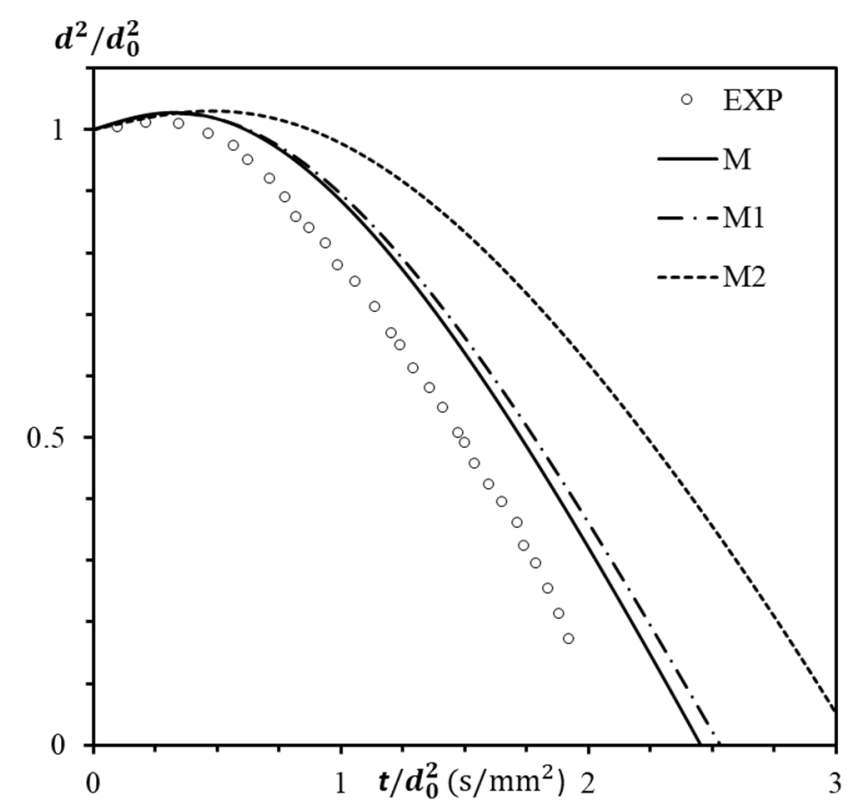

Fig. 3

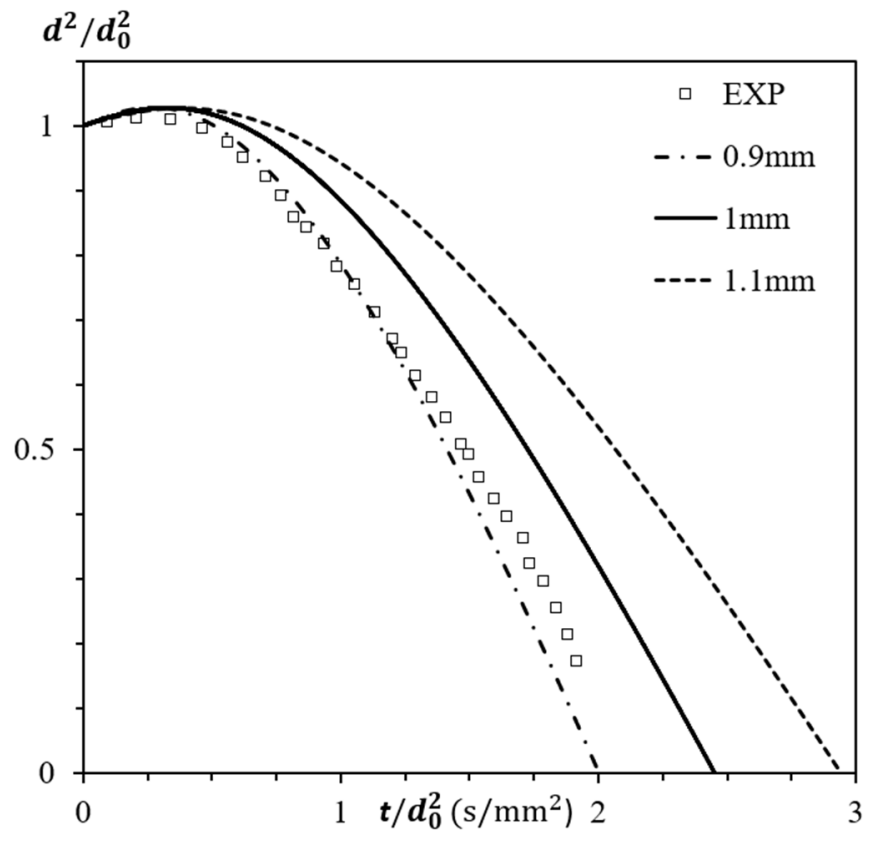

Fig. 4 


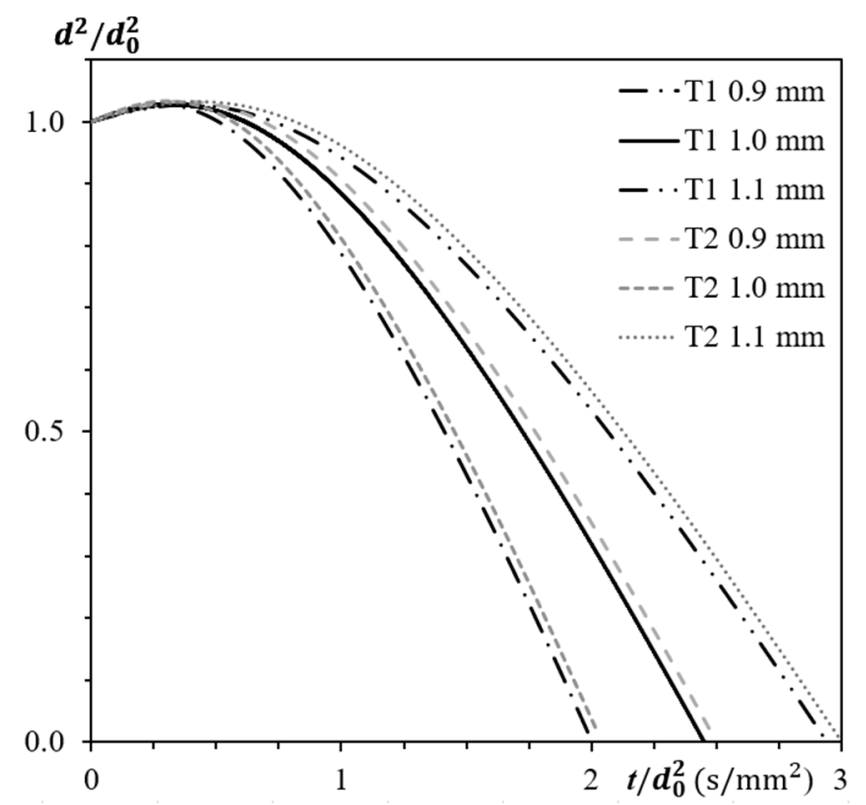

Fig. 5

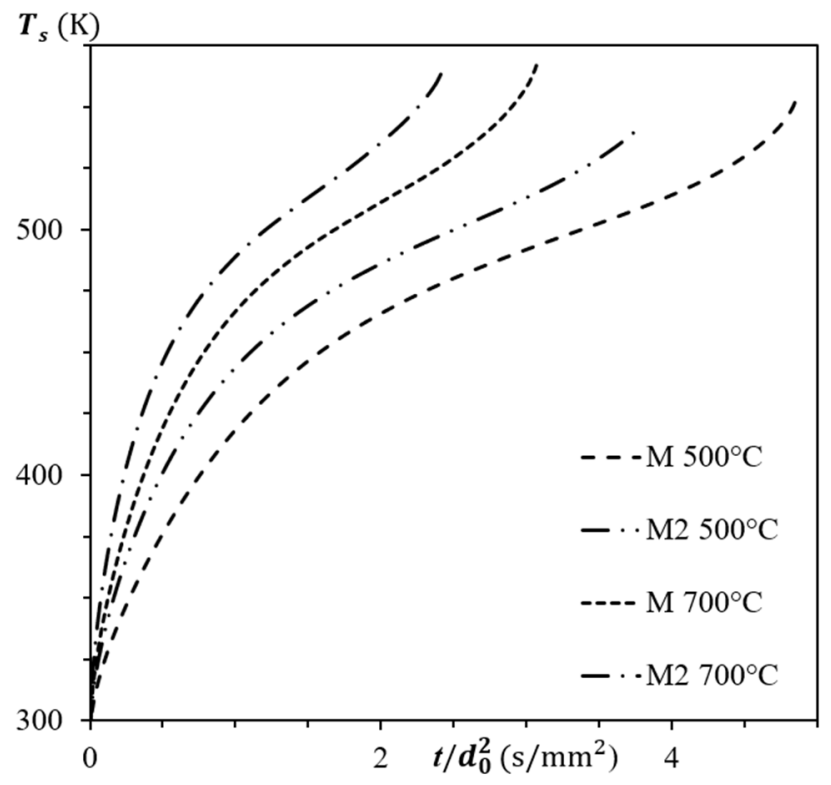

Fig. 6 


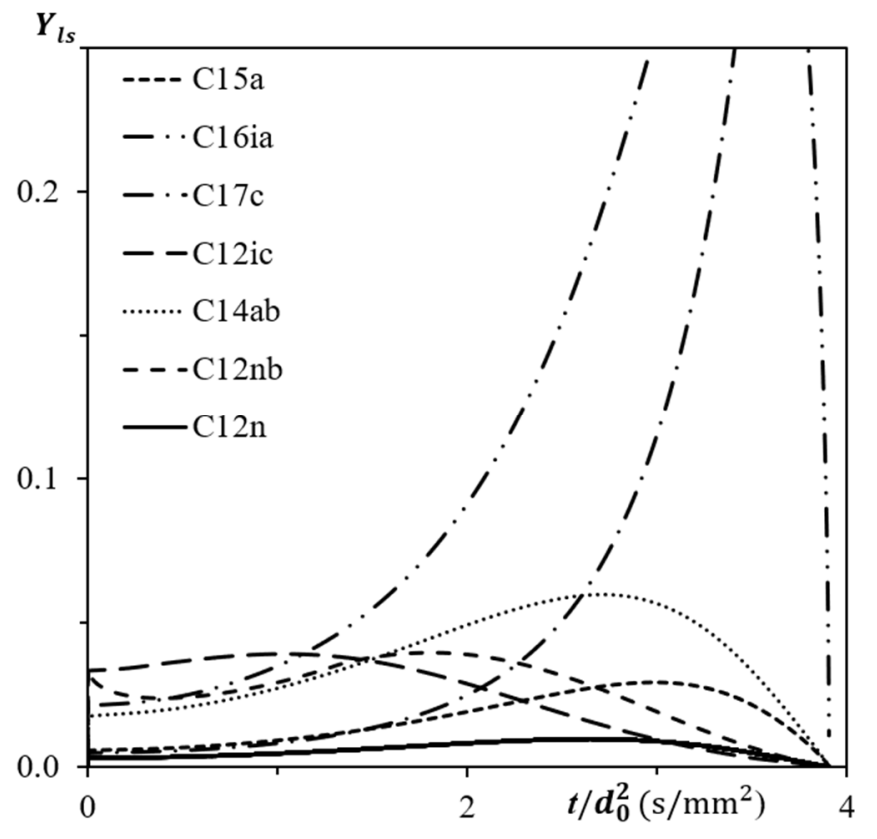

Fig. 7 


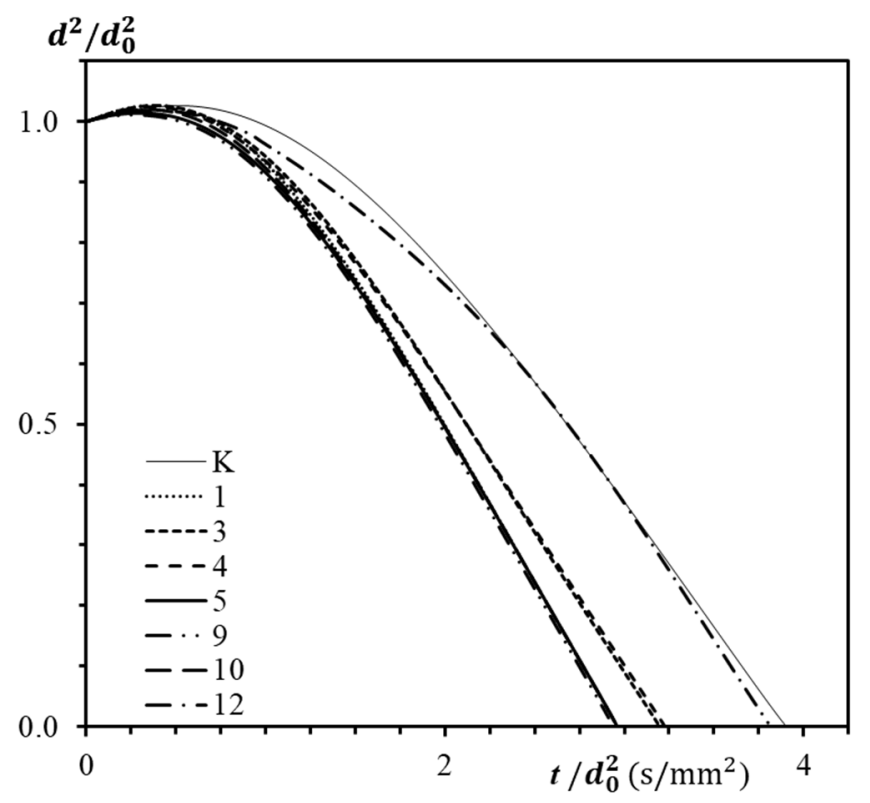

Fig. 8a

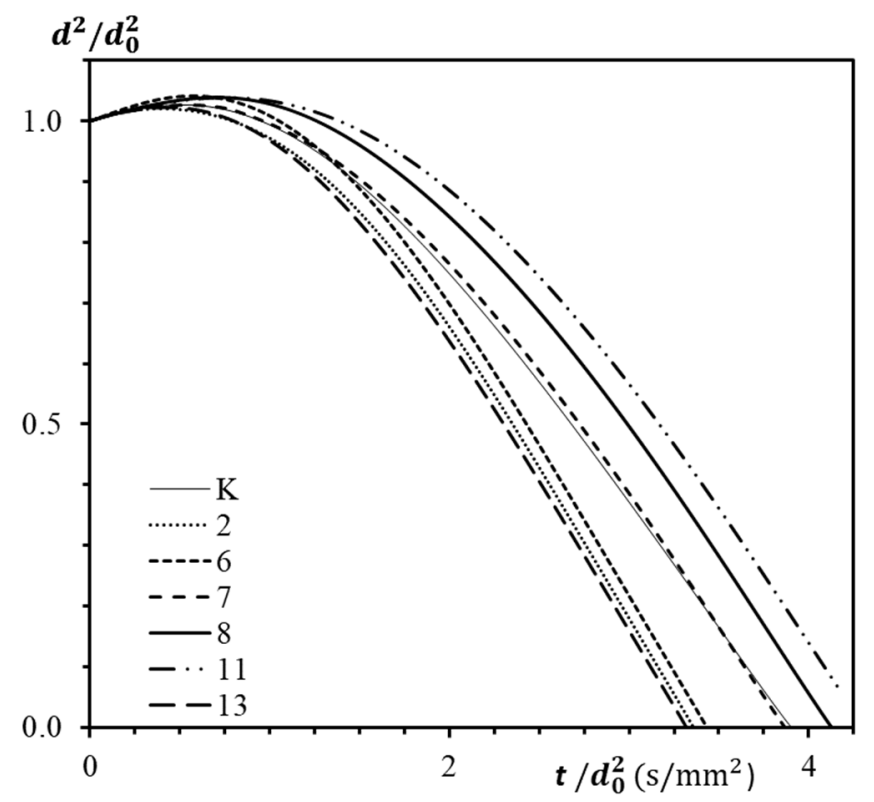

Fig. 8b 


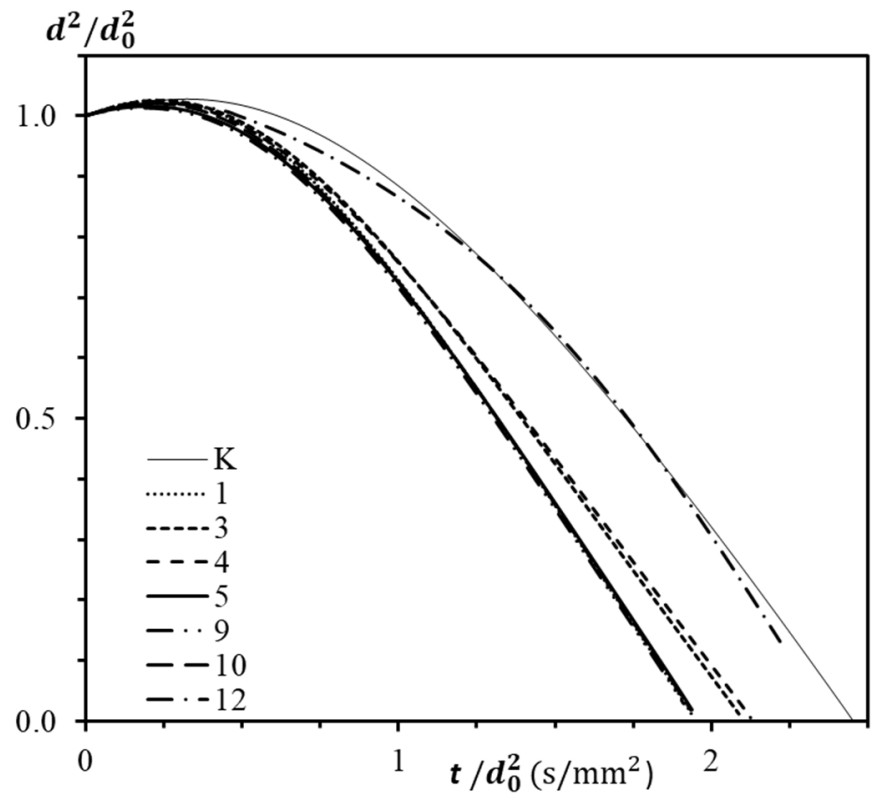

Fig. 9a

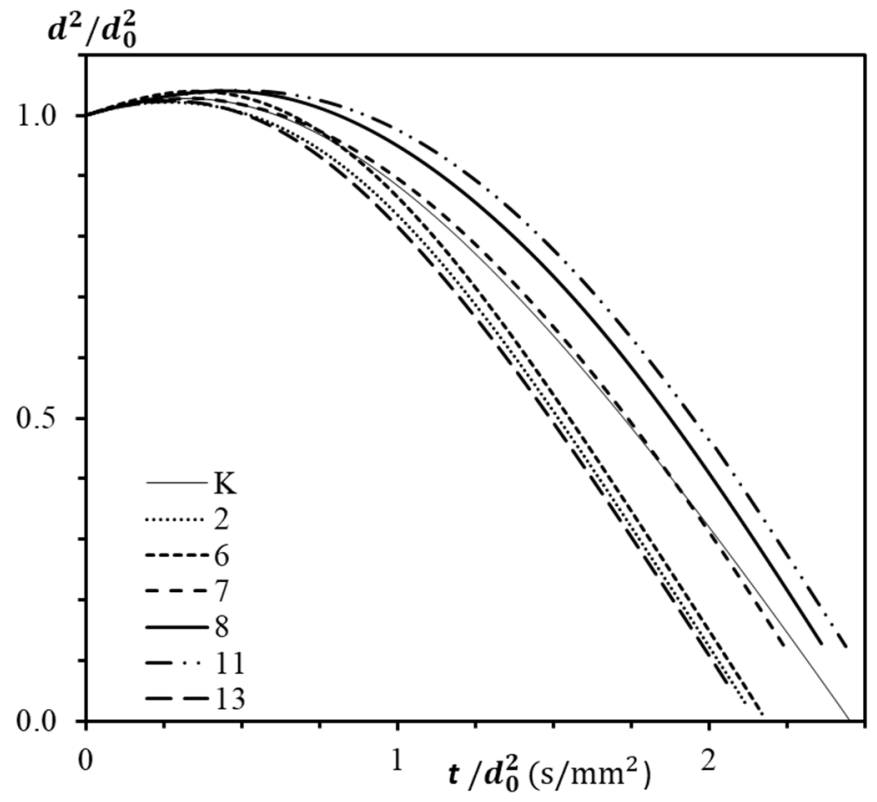

Fig. 9b 


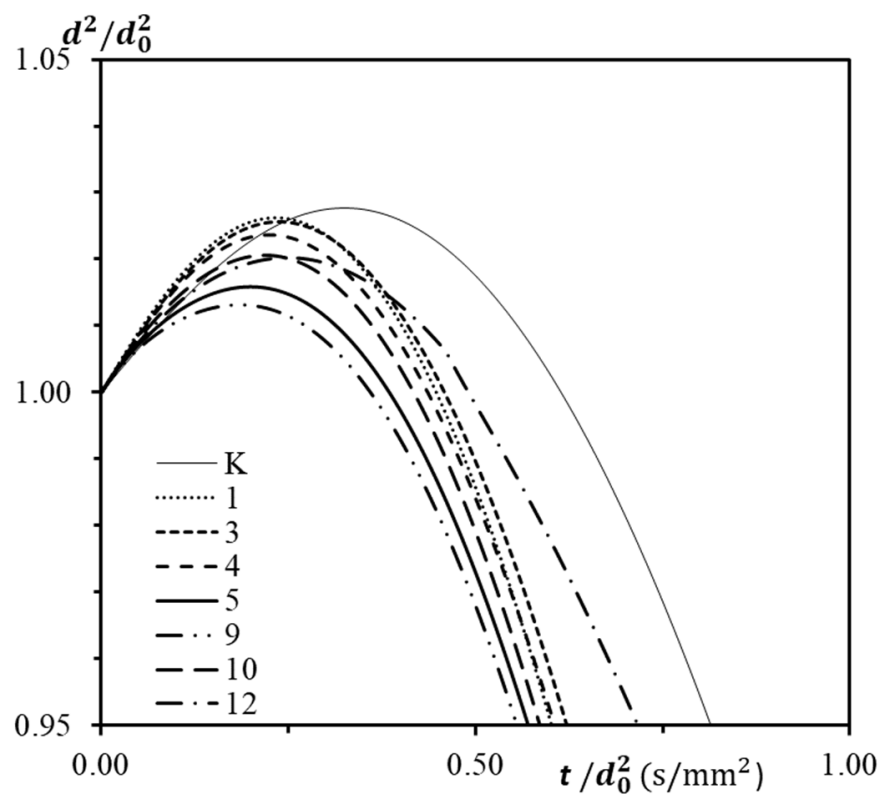

Fig. 10a

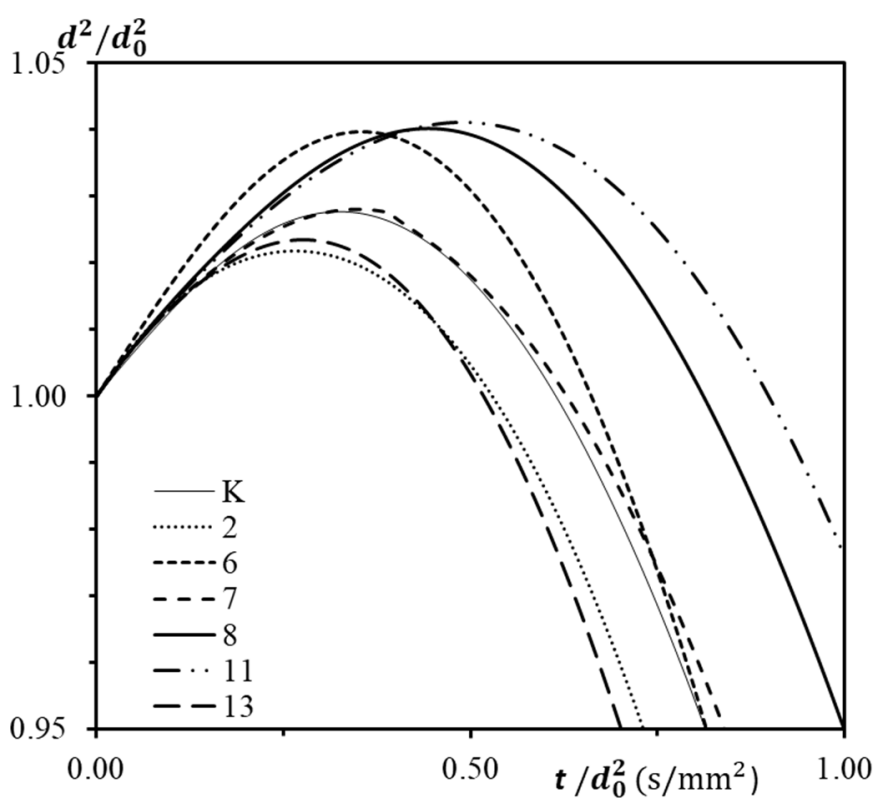

Fig. 10b 


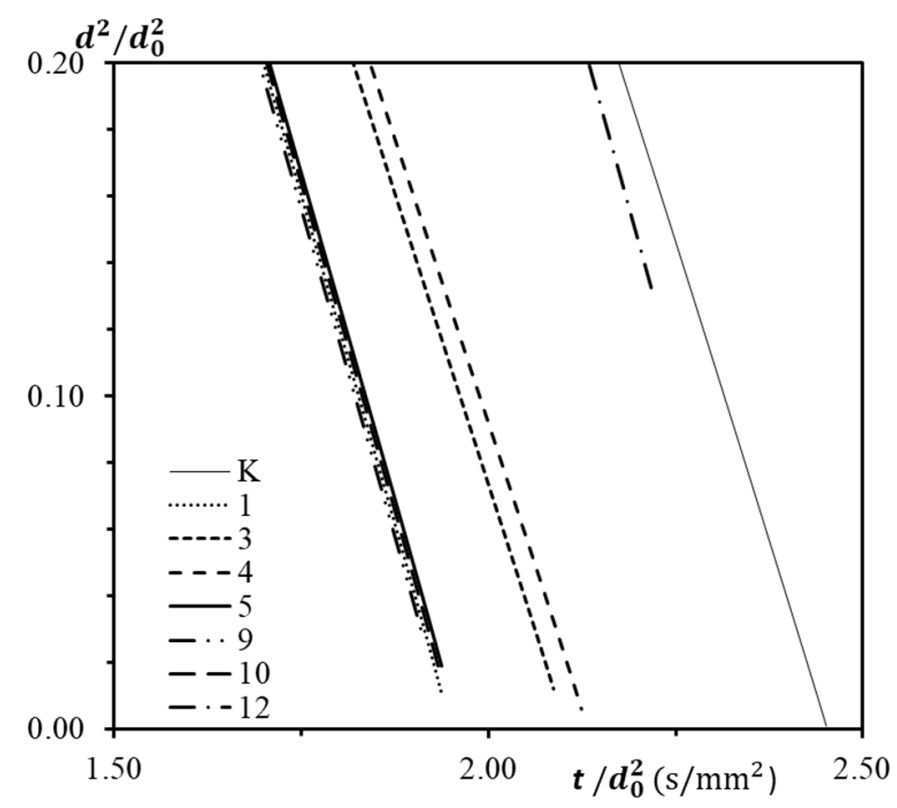

Fig. 11a

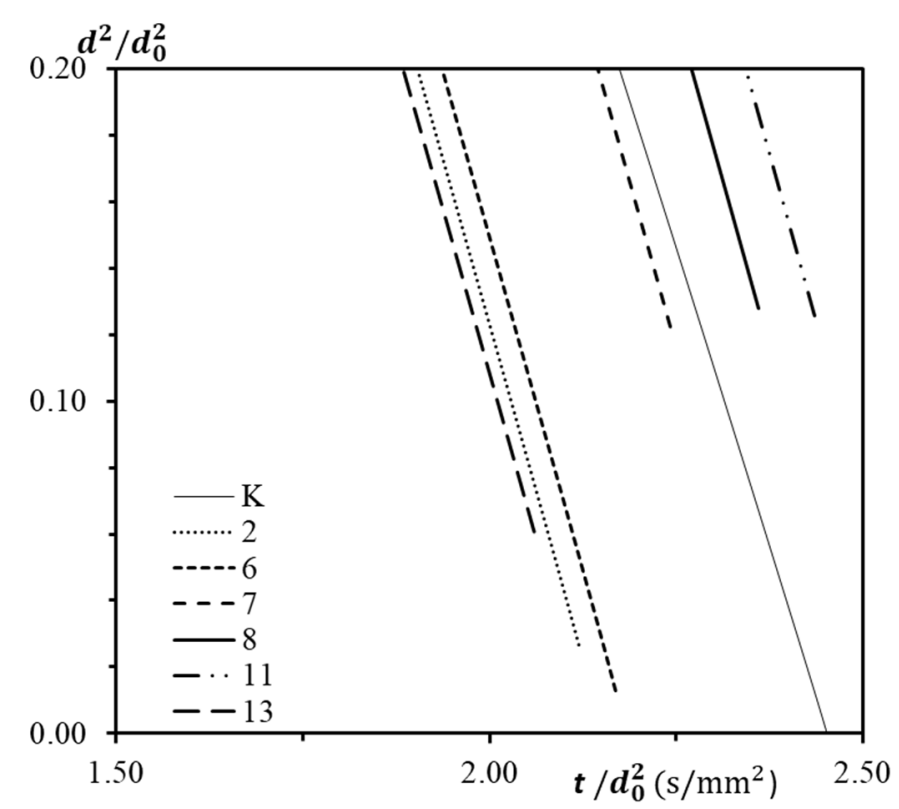

Fig. 11b 


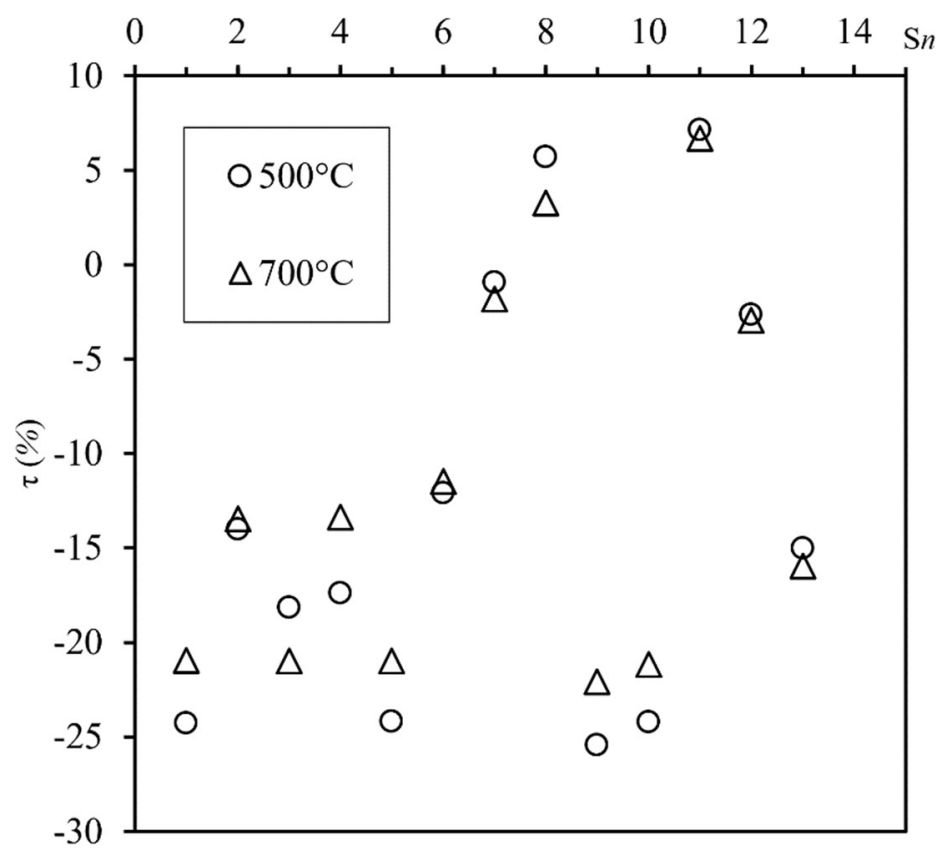

Fig. 12 


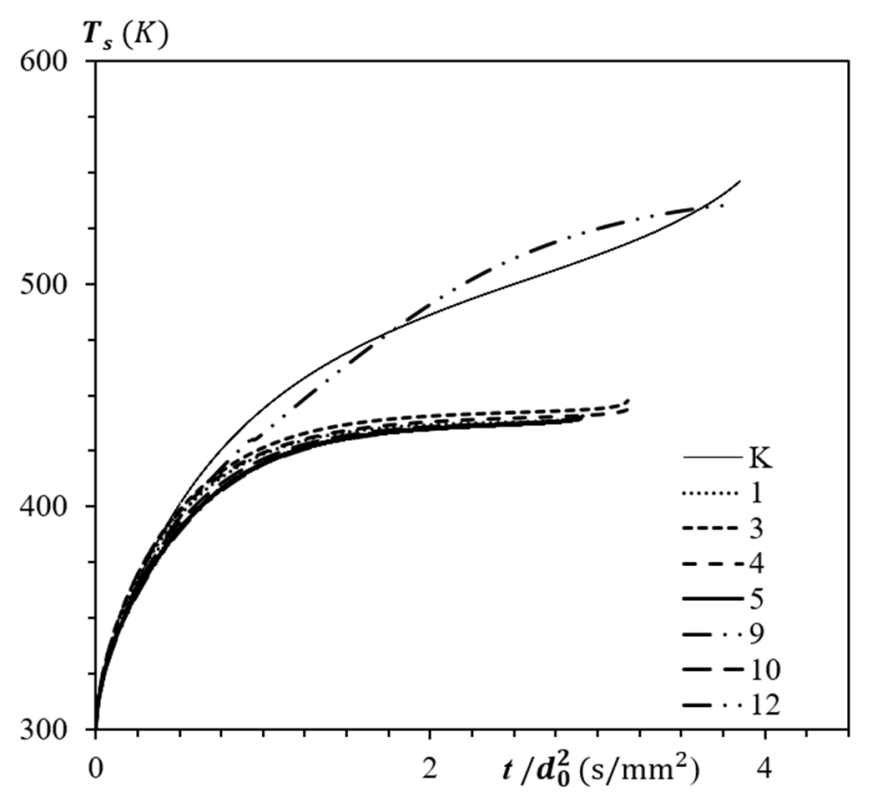

Fig. 13a

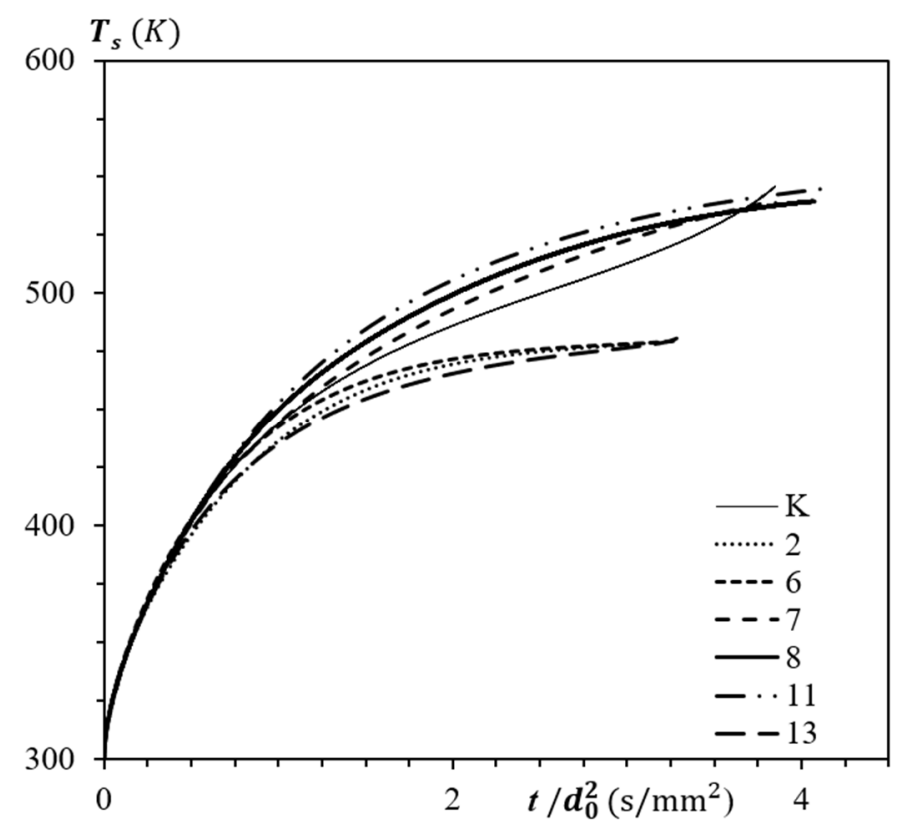

Fig. 13b 


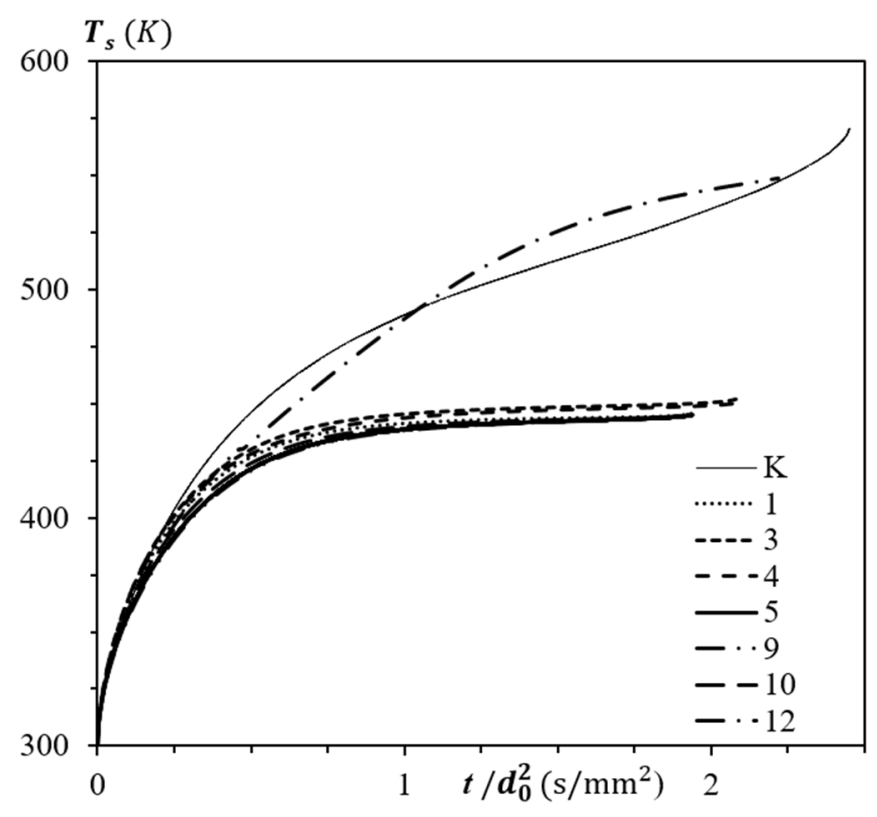

Fig. 14a

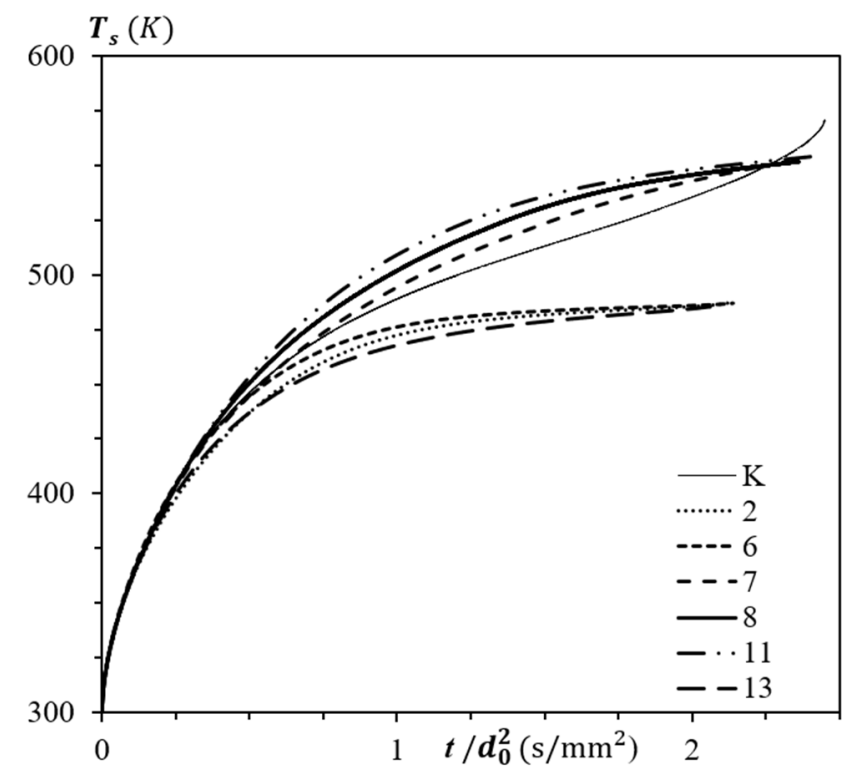

Fig. 14b 


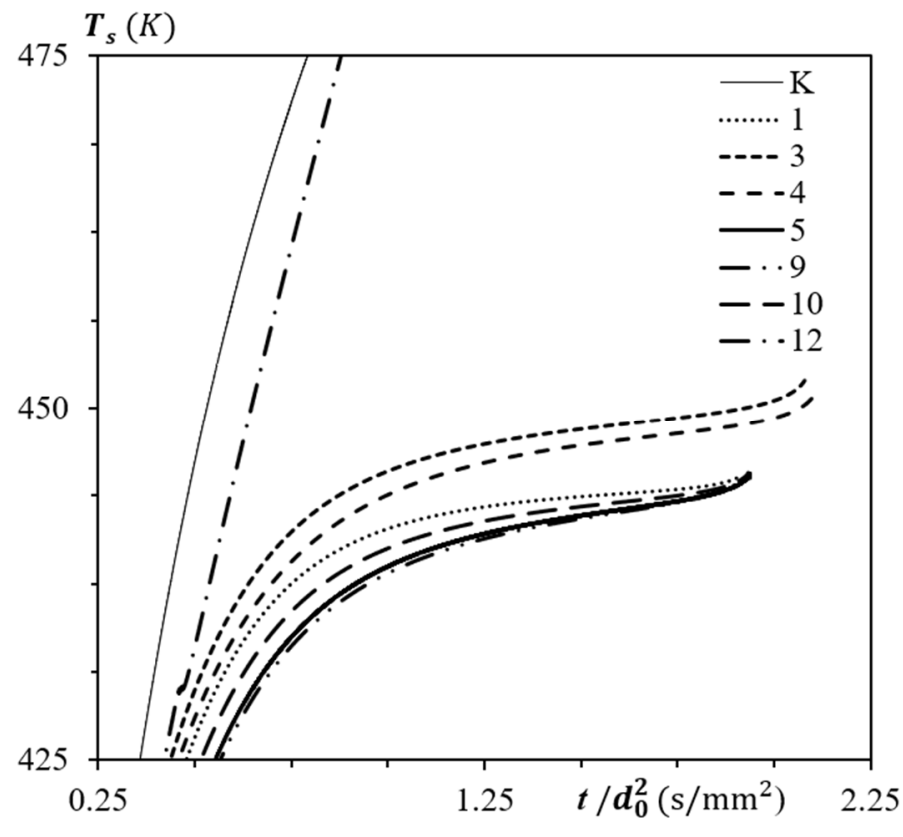

Fig. 15a

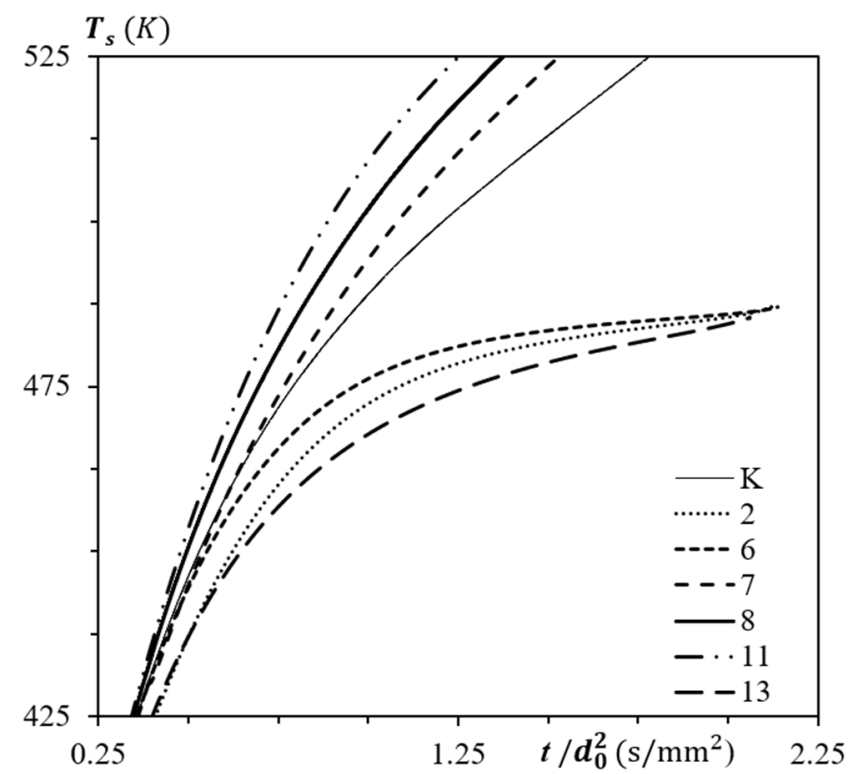

Fig. 15b 